\title{
Microstructure and mechanical properties of aluminium alloy coatings on alumina applied by friction surfacing
}

\begin{tabular}{|c|c|}
\hline Journal: & Part L: Journal of Materials: Design and Applications \\
\hline Manuscript ID & JMDA-20-0074.R2 \\
\hline Manuscript Type: & Original article \\
\hline $\begin{array}{r}\text { Date Submitted by the } \\
\text { Author: }\end{array}$ & 25-Jun-2020 \\
\hline Complete List of Authors: & $\begin{array}{l}\text { Atil, Hasan; University of Applied Sciences Kempten, Mechanical } \\
\text { Engineering } \\
\text { Leonhardt, Matthias; University of Applied Sciences Kempten, Mechanical } \\
\text { Engineering } \\
\text { Grant, Richard; Western Norway University of Applied Sciences, } \\
\text { Mechanical and Marine Engineering } \\
\text { Barrans, Simon; University of Huddersfield, School of Computing and } \\
\text { Engineering }\end{array}$ \\
\hline Keywords: & $\begin{array}{l}\text { friction surfacing, friction coating, Ceramics < Materials by Type, } \\
\text { alumina, aluminium alloy, preheating, thermal shock resistance }\end{array}$ \\
\hline Abstract: & $\begin{array}{l}\text { By combining lightweight metal alloys with ceramics it is possible to } \\
\text { adapt material properties on stressed parts and thus increase stiffness } \\
\text { and/or change the thermal resistance: yet joining such materials is } \\
\text { problematic due to the poor wettability of ceramics by molten metals. In } \\
\text { this work the technique of friction surfacing is used to connect alumina } \\
\text { (Al2O3) with an aluminium alloy (EN-AW 5083). Despite the fact that } \\
\text { Al2O3 has a relatively high coefficient of thermal expansion and a low } \\
\text { thermal shock resistance, specimens have been produced showing } \\
\text { encouraging results. In order to compensate for these material } \\
\text { properties the substrate was preheated to a minimum of } 150^{\circ} \mathrm{C} \text {. In tests } \\
\text { bonding strengths reached } 47.8 \text { MPa and coating thicknesses of } 213 \mu \mathrm{mm} \\
\text { were achieved; results which are comparable with conventional } \\
\text { thermally sprayed coatings. Bonding strengths were determined by using } \\
\text { a pull-off adhesion tester and the coating thickness was measured with a } \\
\text { laser scanning microscope. Analysis of the joint zone shows no clear } \\
\text { evidence of chemical reactions (inter-metallic compounds) or diffusion. } \\
\text { Mechanical interlocking can only be shown to be accountable for } 16 \% \text { of } \\
\text { the bonding strength with investigations turning towards van der Waals } \\
\text { forces and their contribution to adhesion. }\end{array}$ \\
\hline
\end{tabular}

\section{SCHOLARONE" Manuscripts}




\title{
Microstructure and mechanical properties of aluminium alloy coatings on alumina applied by friction surfacing
}

\author{
H.B. Atil ${ }^{\mathrm{a}, \mathrm{b}, \mathrm{c}, *}$, M. Leonhardt ${ }^{\mathrm{b}}$, R.J. Grant ${ }^{\mathrm{a}}$, S. Barrans ${ }^{\mathrm{c}}$ \\ ${ }^{a}$ Western Norway University of Applied Sciences (HVL), Dept. Mechanical and Marine Engineering, Norway \\ ${ }^{b}$ Kempten University of Applied Sciences, Dept. Mechanical Engineering, Germany \\ ${ }^{c}$ Huddersfield University, Dept. Computing and Engineering, United Kingdom
}

\begin{abstract}
By combining lightweight metal alloys with ceramics it is possible to adapt material properties on stressed parts and thus increase stiffness and/or change the thermal resistance: yet joining such materials is problematic due to the poor wettability of ceramics by molten metals. In this work the technique of friction surfacing is used to connect alumina $\left(\mathrm{Al}_{2} \mathrm{O}_{3}\right)$ with an aluminium alloy (EN-AW 5083). Despite the fact that $\mathrm{Al}_{2} \mathrm{O}_{3}$ has a relatively high coefficient of thermal expansion and a low thermal shock resistance, specimens have been produced showing encouraging results. In order to compensate for these material properties the substrate was preheated to a minimum of $150^{\circ} \mathrm{C}$. In tests bonding strengths reached $47.8 \mathrm{MPa}$ and coating thicknesses of $213 \mu \mathrm{m}$ were achieved; results which are comparable with conventional thermally sprayed coatings. Bonding strengths were determined by using a pull-off adhesion tester and the coating thickness was measured with a laser scanning microscope. Analysis of the joint zone shows no clear evidence of chemical reactions (inter-metallic compounds) or diffusion. Mechanical interlocking can only be shown to be accountable for $16 \%$ of the bonding strength with investigations turning towards van der Waals forces and their contribution to adhesion.
\end{abstract}

Keywords: friction surfacing, friction coating, aluminium alloy, alumina, ceramics, preheating, thermal shock resistance

\footnotetext{
*Corresponding author. Tel.: +49 (831) 2523233

Email address: hasan.atil@hs-kempten.de hbah@hvl.no (H.B. Atil) 


\section{Introduction}

The process of joining metals with ceramics proves to be a challenge for modern material science. Naidich et al. [1] performed investigations on the wettability of various ceramic materials and developed complex brazing technologies. Due to the poor wettability by metals it is very difficult and technologically complex to join these dissimilar materials. Metal-ceramic bonding strengths tend to be low and are not sufficient for typical areas of application such as lightweight components and high temperature applications.

State of the art joining technologies such as reactive air brazing or diffusion bonding of ceramics are very expensive and time consuming [2]. A more cost effective and efficient solution could be to join such dissimilar materials through friction surfacing processes.

Friction surfacing is a variation on friction welding methods, where the heat produced by friction is used to locally soften metal. Whilst in friction welding two separate bodies are joined by relative motion and rubbing of the contacting surfaces against each other [3] friction surfacing, also known as friction coating, is suitable to provide an areal (continuous) coverage on a metal substrate; thereby producing a sealed surface. This surface finish can be used, for example, for the purpose of corrosion and wear protection or the repair of worn engineering parts. This surfacing technique is well developed and is predominantly used for coating metal substrates with metals. Gandra et al. [4] gives a broad overview of the technology and its area of application. The process utilizes a rotating disc or rod consisting of coating material which is pressed against a substrate. The heat generated through friction between the two materials plasticises the coating material which is then moved along the substrate producing a surface layer. The generated heat and applied pressure leads to the formation of new bonds between the two materials. Stegmueller et al. [5] state that for material combinations in which the generated heat at the friction zone is too low, additional sources such as inductive heating can be used. Figure 1 shows the basic principle behind the technique. 


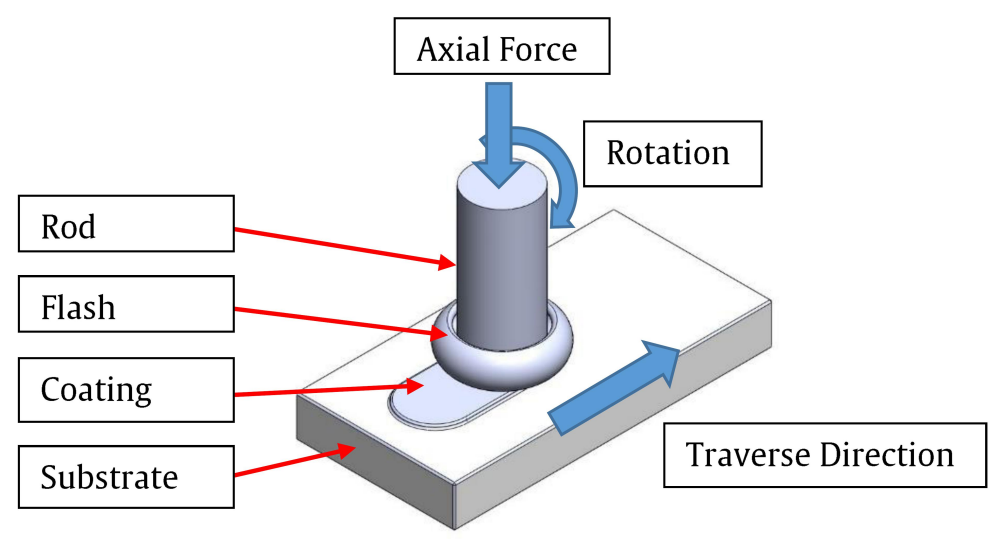

Fig. 1. Friction surfacing [6].

Friction surfacing has the potential to be used for a wide range of metal-material combinations and applications, enabling the selective and local modification of material properties. Gandra et al. [7] present work where soft metal coatings are applied on tough metal substrates such as mild steel on carbon steel and Rao et al. [8] produces aluminium coatings on titanium. Where as Stegmueller et al. [5] show the converse with the application of tough metal coatings on soft metal substrates; in this case austenitic stainless steel on aluminium, combined with an initial softening of the consumable rod.

The friction surfacing of ceramics has received very little attention, with research restricted to one article in a trade magazine of the Welding Institute in Abington, Cambridge UK [9]. The author Mirlashari demonstrated that tracks of aluminium only a few millimetres wide and less then $50 \mu \mathrm{m}$ thick could be formed on a ceramic substrate. Evidence of friction surfacing over large surface areas, so producing material composites, has not been found and there are no known publications in this area since this article in 2009. Gandra et al. [4] presents an extensive overview of various material combinations using the technique of friction surfacing. It was noted that only metal to metal composites and reinforced coatings, in which reinforcement particles are mixed within the coating metal matrix, have been produced. Isolated publications deal with the joining of ceramics with metals by friction welding. As described by Manteghi [10], friction welding is a technique in which one component is rotated at high speed and pressed against another stationary component. The generated heat at the friction zone plasticises the materials. The rotation is then stopped, whilst maintaining the axial force for a short period of time, so producing a weld. With friction welding it is also possible to join dissimilar materials, but the geometry is limited to rotationally symmetric 
parts in which the shape and the surface of the materials cannot be varied. Fernie [3] demonstrates that metal-ceramic combinations produced by friction welding are feasible, but tend to have low shear strength. It is stated that oxide ceramics appear to bond better than non-oxides and that materials with a high coefficient of thermal expansion bond better to aluminium (e.g. $\mathrm{ZrO}_{2}=10$ $\left.\mathrm{x} 10^{-6} /{ }^{\circ} \mathrm{C}, \mathrm{AlN}=4.2 \times 10^{-6} /{ }^{\circ} \mathrm{C}, \mathrm{Al}=23.5 \times 10^{-6} /{ }^{\circ} \mathrm{C}\right)$. It was commented that these two material characteristics could be related to each other since most oxide ceramics tend to have a relatively high thermal expansion. To increase the shear strength of the metal-ceramic compound Pietrzak [11] proposes a technique in which $\mathrm{Fe}_{3}-$ and $\mathrm{Ni}_{3}$ - based intermetallics are used as an intermediate piece for joining steel and alumina parts.

Fauzi et al. [12] offers a deep insight in welding YSZ-alumina composites to 6061 aluminium alloy rods. It was observed that higher rotational speeds up to $2500 \mathrm{rpm}$ can produce better joints with higher bonding strength then lower speeds. Uday et al. [13] claims that higher rotational speeds lead to higher temperatures in the friction interface. It was pointed out that the frictional heat generated at the interface is important for the quality of the joint thus thermal conductivity, thermal diffusivity and heat capacity of used materials was investigated. It is stated that thermocouples used to measure the temperature during the coating process were attached to the ceramic composite rod at various distances from the interface and a temperature of $125.4^{\circ} \mathrm{C}$ at a rotational speed of 2500 rpm was measured.

By adapting and enhancing existing knowledge about friction surfacing of metals with metals (such as the employment of coating rod preheating, changes in process parameters and experimental setups) to the coating of ceramics with metals, the advantages of this process can be used to develop a new technique for manufacturing ceramic-metal composites. These coated ceramics can then be integrated into metallic assemblies by using traditional joining techniques such as micro welding or brazing.

The current work presents the potential for a new low-cost, reliable and robust surfacing technique for ceramics based on the technique of friction surfacing.

The adaptation of friction surfacing to encompass metal-ceramic compounds provides the possibility for a wide range of new applications which is perhaps particularly applicable to transportation related sectors: from automotive to aviation, with other fields of application becoming apparent. By way of example, ceramic-metal joints are used in vacuum tubes, transistor packages, sapphiremetal windows and rocket igniter bodies [14]. In the field of lightweight constructions there is a 
requirement in many structures to provide localised specific material characteristics. Often the base material is unable to provide the required properties of wear resistance, heat resistance or stiffness; but by inserting ceramic inlays at appropriate places these requirements could be met.

\section{Experimental setup and method}

One of the benefits of friction surfacing is the simple setup needed. As a result, most milling machines can be refashioned and retrofitted with equipment for carrying out experimental tests. In this case a laser cutting machine has been modified (DMG Mori Co., Germany, Model: Maho MH700) whereby the laser has been replaced by a high-frequency spindle drive, which is mounted on a carriage (see Figure 2). To keep the axial force constant during the surfacing process a pneumatic cylinder has been mounted between the spindle and machine head. 


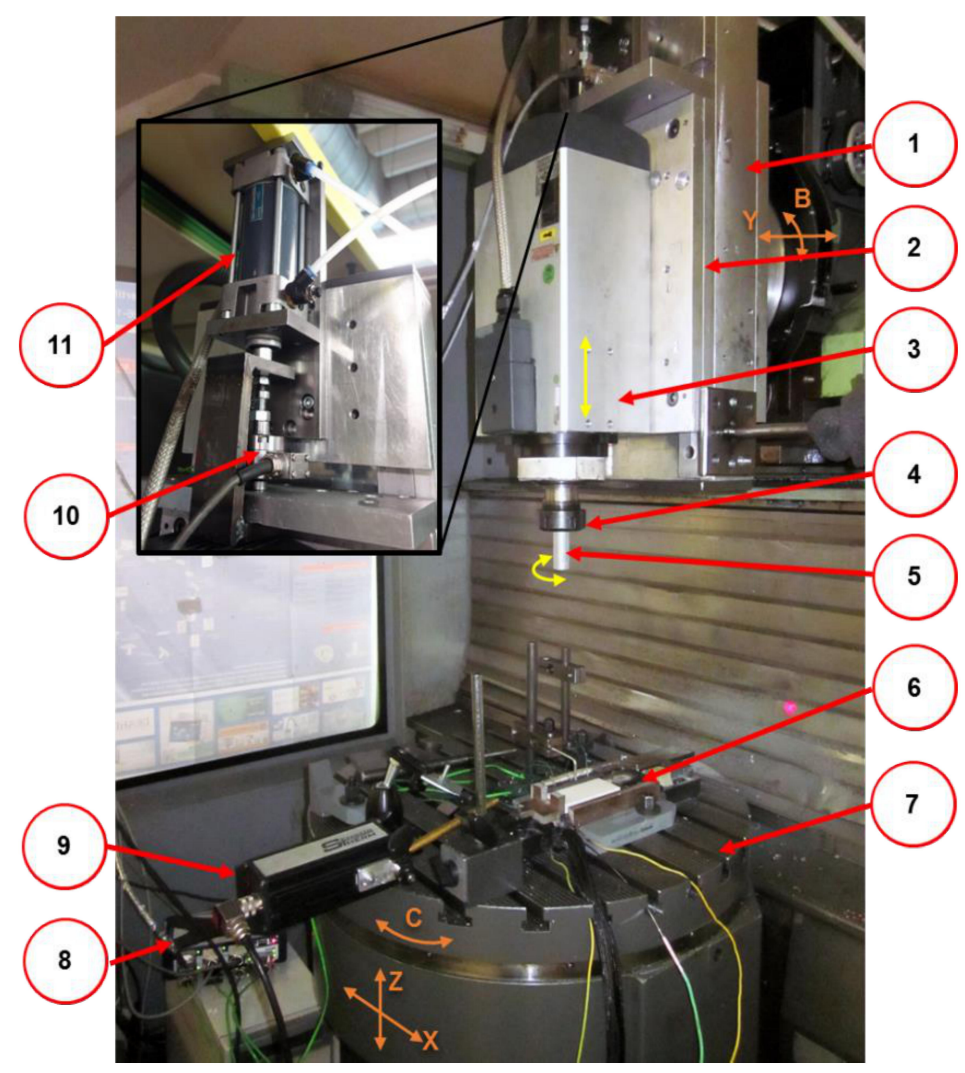

\begin{tabular}{|l|l|}
\hline \hline 1 & Converted machine tool \\
\hline 2 & Slide \\
\hline 3 & Spindle \\
\hline 4 & Collet \\
\hline 5 & Coating rod \\
\hline 6 & Clamping device \\
\hline 7 & Machine bed \\
\hline 8 & Data logger \\
\hline 9 & Pyrometer \\
\hline 10 & Load cell \\
\hline 11 & Pneumatic cylinder \\
\hline
\end{tabular}

Fig. 2. Machine set-up [15].

http://mc.manuscriptcgntral.com/(site) 
To apply a coating onto the substrate the specimen has to be preheated and clamped in place while moving the rod over the surface. Jahanmir et al. [16] gives an overview of ways and means of machining and clamping ceramic materials. He states that when clamping ceramics the specific characteristics of the material have to be taken into account as local load peaks could induce cracking. Thus the substrate clamping device needed to provide a uniform force over an extended area of the workpiece. Also, by employing a heating device for preheating the substrates the effects of thermal shock can be reduced and thus the propensity for cracks to initiate in the substrate during the surfacing process. Preliminary trials showed that a preheating temperature of $150^{\circ} \mathrm{C}$ reduced the probability of fracture greatly. As such, a new device had to be designed and manufactured.

Figure 3(a) shows the clamping device design. The heating of the substrates was carried out with two high performance heating cartridges (Tuerk \& Hillinger, Germany, Model: HLP 125099) which generate heat by electrical resistance and could reach temperatures of up to $750^{\circ} \mathrm{C}$. The heating cartridges do have a maximum output power of 1000 Watts and a heating rate of 20-24 $\mathrm{W} / \mathrm{cm}^{2}$. The clamping force was evenly distributed by a special pull-down clamp and clamping jaw. To reduce heat dissipation the substrate and heating plate was surrounded by synthetic resin bonded paper. This paper has a grade 4 resistance to incandescence and is not able to combust at the preheating temperatures used. 
(a)

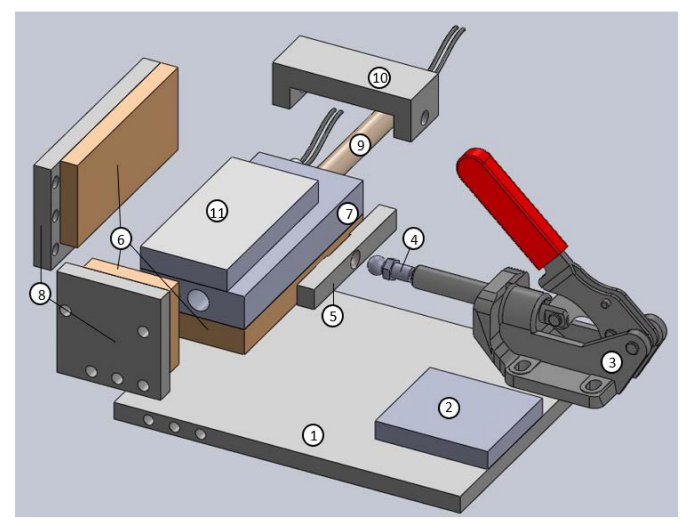

\begin{tabular}{|l|l|}
\hline \hline 1 & Baseplate \\
\hline 2 & Support \\
\hline 3 & Pull-down clamp \\
\hline 4 & Spherical-head-screw \\
\hline 5 & Clamping jaw \\
\hline 6 & Isolation \\
\hline 7 & Heating plate \\
\hline 8 & Stop plate \\
\hline 9 & Heating cartridge \\
\hline 10 & Starting plate \\
\hline 11 & Substrate \\
\hline
\end{tabular}

(b)

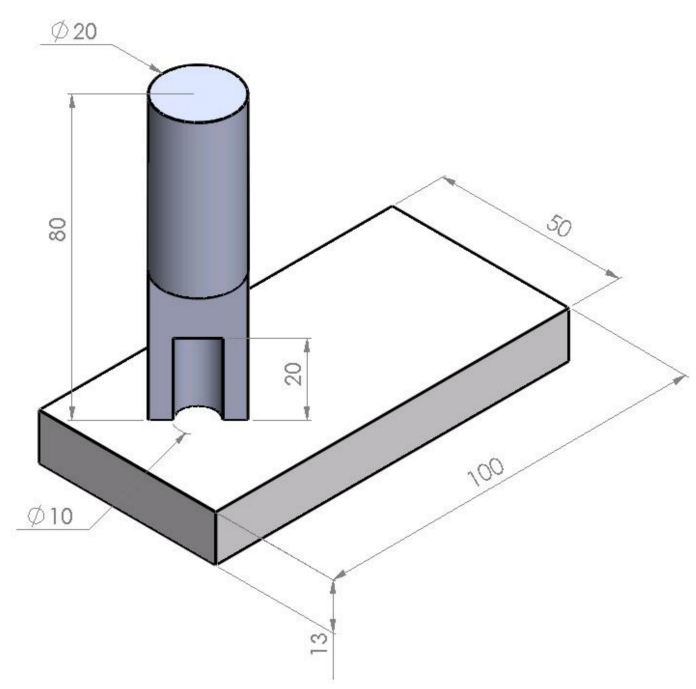

Fig. 3. Sketches showing (a) clamping device design [6] and (b) specimen dimensions.

\subsection{Material selection}

Alumina is one of the most widely used technical ceramic [17]. It can be used at temperatures up to $1900^{\circ} \mathrm{C}$ [18] and has excellent wear-resistance, breaking strength and high rigidity. Higher volumes can be purchased cheaply. Due to these material characteristics alumina $\left(\mathrm{Al}_{2} \mathrm{O}_{3} 92 \%\right)$ has been chosen as a substrate material.

Aluminium and its alloys are lightweight, ductile and easy to process. The low melting point and good formability is beneficial for the friction surfacing process. To facilitate further joining, after the surfacing process, the chosen aluminium alloy should be weldable. This limits the material 
choice to the EN AW-5xxx group of alloys. This group has the highest strength of the non-heat treatable alloys and especially the AlMgMn grades are characterised by a good weldability [19]. Consequently for the coating material aluminium EN-AW $5083\left(\mathrm{AlMg}_{4.5} \mathrm{Mn}_{0.7}\right)$ represented a good choice and was used.

\subsection{Material preparation}

The test materials used in this study were commercial grade EN-AW 5083 aluminium alloy rods and 92\% alumina plates, as shown in Figure 3(b)

The alumina plates had dimensions of 150x100x13 mm and where cut in three equal parts $(50 \mathrm{~mm})$ with a diamond saw blade. The $20 \mathrm{~mm}$ aluminium rods were cut from a $3000 \mathrm{~mm}$ standard stock section bar. Preliminary trials where carried out which led to cracking at the centre of the substrate, as seen in Figure 4. Lawn [20] shows that localised stresses induced by blunt indenters can lead to crack formation in brittle solids and thus degradation in the strength. In our case the circumferential speed of the rod decreases in proportion to the diametral position and, as such, is zero at the centre of the rod; with the lack of frictional heating and plastisization causing a stress peak. To reduce these surface pressure peaks on the alumina plates during the surfacing process the rods were drilled axially with a $10 \mathrm{~mm}$ hole effectively creating a thick walled tube. It was found that by removing this core material in conjunction with a preheating of the substrate to $150^{\circ} \mathrm{C}$ crack formation was diminished.

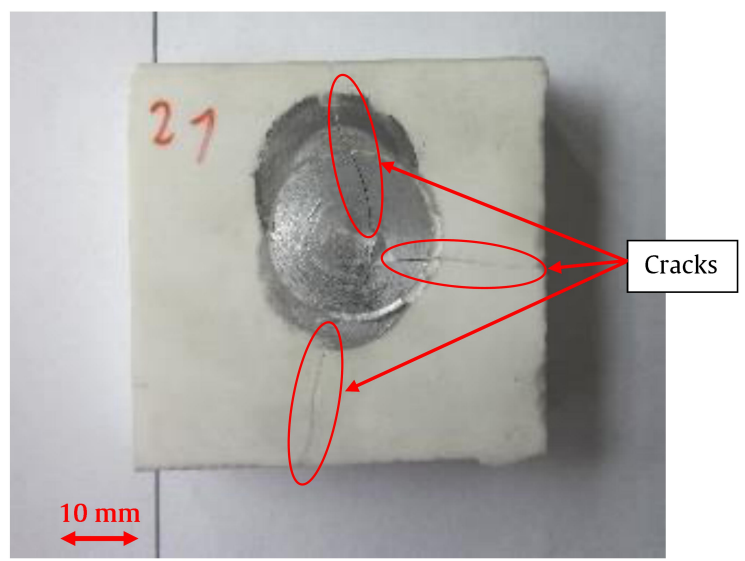

Fig. 4. Cracking at the centre of the specimen.

The end surfaces of the aluminium rods where deburred and cleaned with isopropanol. The ceramic substrates needed to be as flat as was practicable when fixing in the clamping device; 
otherwise the axial forces of the process would lead to critical tensile stresses in the alumina plate and thus result in crack initiation. To improve the flatness and to remove the inhomogeneous sinter skin the surfaces of the alumina plates where ground, chamfered and degreased.

\subsection{Data acquisition}

For the evaluation of the bonding quality various measurement data was recorded which included axial force, coating temperature and preheating temperature. Because of the sensitivity to thermal shock of the ceramic substrate, the temperature of the coating rod was required to be measured during the process. This was in an attempt to comprehend the effects of the thermal stress induced by friction surfacing. For this purpose, a pyrometer (Sensortherm Co., Germany, Model: Metis MI18) with integrated optics was used with the recording, analysis and verification of the data carried out on a computer. The device was positioned at a distance of approximately $250 \mathrm{~mm}$ and focused on a $2 \times 2 \mathrm{~mm}$ measuring zone at the centre of the coating rod. Since the temperature at the surface of the aluminium rod was measured an emissivity of 0.2 was chosen [21]. In [22] it was noted that emissivity values may be subject to change when heating to temperatures above $600 \mathrm{~K}$ to $700 \mathrm{~K}\left(327^{\circ} \mathrm{C}\right.$ to $\left.427^{\circ} \mathrm{C}\right)$ and over an extended period of 1 to 10 hours; temperatures measured in this work were above these values, but with test durations in the order of 1 minute. As such, pyrometer temperatures have been used for the purposes of comparison and have not been used in the analyses. To determine the temperature of the ceramic substrate type $\mathrm{K}$ thermocouples were mounted on the surface of the alumina plate. This allowed optimised preheating of the substrate and in-situ measurement of the heat transfer outside of the friction zone.

Previously published work by Uday et al. [13] measured the interfacial temperature by placing Type $\mathrm{K}$ thermocouples at various distances from the interface. In his work a temperature of $125.4^{\circ} \mathrm{C}$, at a rotational speed of $2500 \mathrm{rpm}$, was measured. It is stated that thermocouples used to measure the temperature during the process were attached to the ceramic composite rod at various distances from the interface. However, it would seem that this approach would not measure the temperature within the interface, but the temperature on the outer surface of the ceramic rod. For an accurate measurement of the interface temperature the thermocouple must be placed onto the surface in which the heat is generated. This comment on Uday's work is substantiated by Li et al. [23] whose work on friction welded copper/alumina dissimilar joints measured an average temperature of $370^{\circ} \mathrm{C}$ at the interface when using a rotational speed of $1900 \mathrm{rpm}$. A new approach to gain a temperature measurement has been used in the presented work. Alumina plates where prepared 
with $2 \mathrm{~mm}$ wide and $25 \mathrm{~mm}$ long slots running transversely to the path of the friction rod to measure the heat generated in the friction interface. Type $\mathrm{K}$ thermocouples were installed in these slots fixed in place using high temperature resistant sodium silicate paste. Figure 5 shows the setup before 5(a) and after the surfacing process $5(\mathrm{~b})$.

(a)

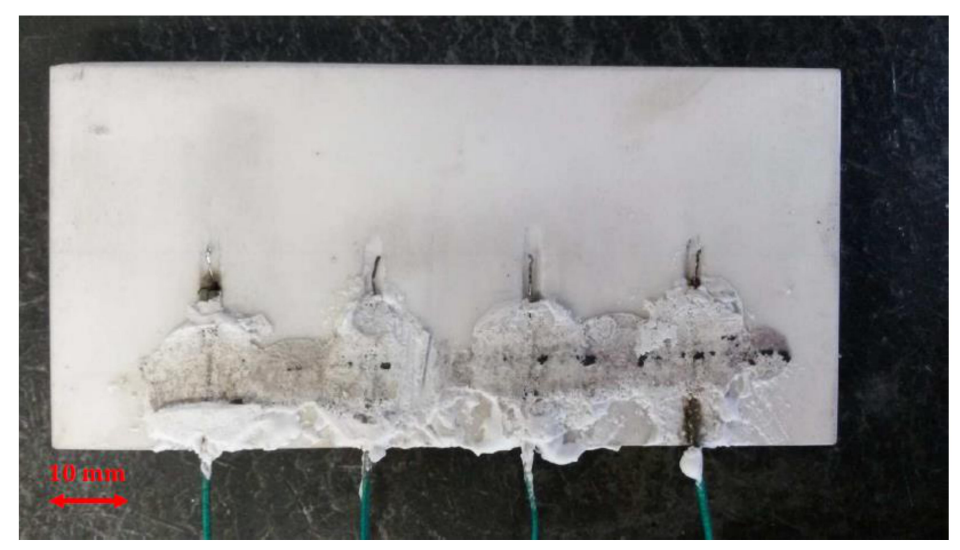

(b)

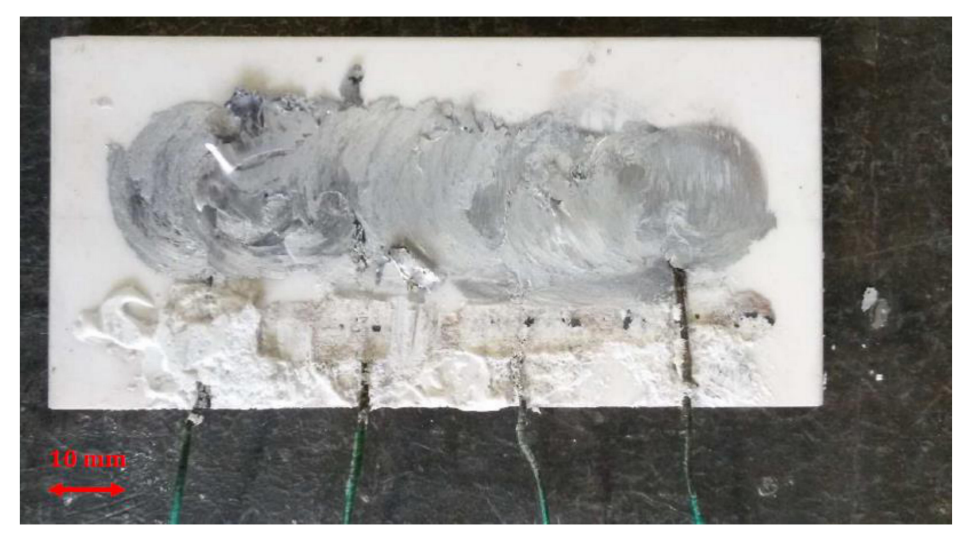

Fig. 5. Pictures showing prepared specimen (a) before surfacing, and (b) after surfacing.

To determine the friction pressure the axial force was measured by a load cell attached between the spindle drive and the pneumatic cylinder (see Figure 2).

The alumina plates were preheated using the heating elements installed in the clamping device and then clamped. This was to alleviate the stresses produced as a result of the thermal expansion. After this preheating the coating rod was spun up to the required speed and pressed onto the substrate. The axial pressure and heat generated through friction led to the formation of a flash at the tip of the rod whereupon the feed was started. In relation to the findings of Fauzi et al. [12], 
where higher rotational speeds are shown to produce better joints (i.e. 1250, 1800, $2500 \mathrm{rpm}$ ), rotational speeds of 3000, 4500, $6000 \mathrm{rpm}$ were selected. Axial force, travel speed and preheating temperature were also varied (see Table $\mathrm{I}$ in section 2.6).

After the surfacing process, the specimens were taken out of the clamping device and set aside for cooling down in air at room temperature. To investigate the effects of multiple variables on the bond quality, i.e. the bonding strength and coating thickness, a statistical design of experiments tool was used (Minitab Inc., USA, Software: Minitab) [24] (see Section 2.6).

\subsection{Bonding strength}

To determine the bonding strength between the substrate and the coating a commercially available adhesion tester was used (DeFelsko Co., USA, Model: Positest AT-A) (see Figure 6(a)). This is a portable pull-off adhesion tester which measured the force required to pull a circular section of the coating away from the substrate. The pull-off strength was then calculated from the pull-off force measured and shown on the integrated display [25].

The coated samples were cut in three equal parts. The first third was used for the pull off test. The second for metallurgical investigations and the remaining part as a possible substitute if the pull off test was to fail. In order to guarantee the accuracy and the repeatability of the test a defined surface area was detached from the coating. For this purpose, a diamond hollow-core drill with an inner diameter of $10 \mathrm{~mm}$ was used. This ensured that only the bonding strength of the coating material in this specific area was measured. Figure 6(b) shows the prepared specimen and the drill used.

The drilled area was then cleaned, removing any grease and dirt with isopropanol. A dolly of a diameter appropriate to the drilled area was glued on to the prepared region with a special adhesive (HTK Co., Germany, Product: Ultrabond 100). The single-component adhesive used is specially designed for pull off tests according to DIN EN 582 and has an average bond strength of $102 \mathrm{MPa}$. According to Boutar et al. [26] the bond strength depends on the surface roughness and the adhesive layer thickness. Also, the increase in surface roughness reduces the wettability and thus the strength of the bond. An excessive adhesive layer thickness will lead to an increase in the number of pores and bonding failures within the adhesive . Values for roughness of $\mathrm{Rt}=30 \mu \mathrm{m}$ and a curing contact pressure of $0.7 \mathrm{~N} / \mathrm{mm}$ for a layer thickness of $0.2-0.3 \mathrm{~mm}$ is recommended by the manufacturer. This was established by abrading the dolly and coating surfaces with steel wool, and then clamping the dolly to the specimens to achieve the required contact pressure. The adhesive 
was cured for 35 minutes at a temperature of $190^{\circ} \mathrm{C}$ in a laboratory furnace. This would not have affected the microstructure of the coated material (i.e. EN-AW 5083) because no percipitation hardening is occuring for this alloy [19]. Figure 6(c) shows the dolly glued on to the specimen which is ready to be tested. The pull off tests were carried out with a pull rate of $3.00 \mathrm{MPa} / \mathrm{s}$ and a dolly diameter of $10 \mathrm{~mm}$. These parameters were entered into the testing device to get a direct reading of the bonding strength in MPa on the integrated display.

(a)

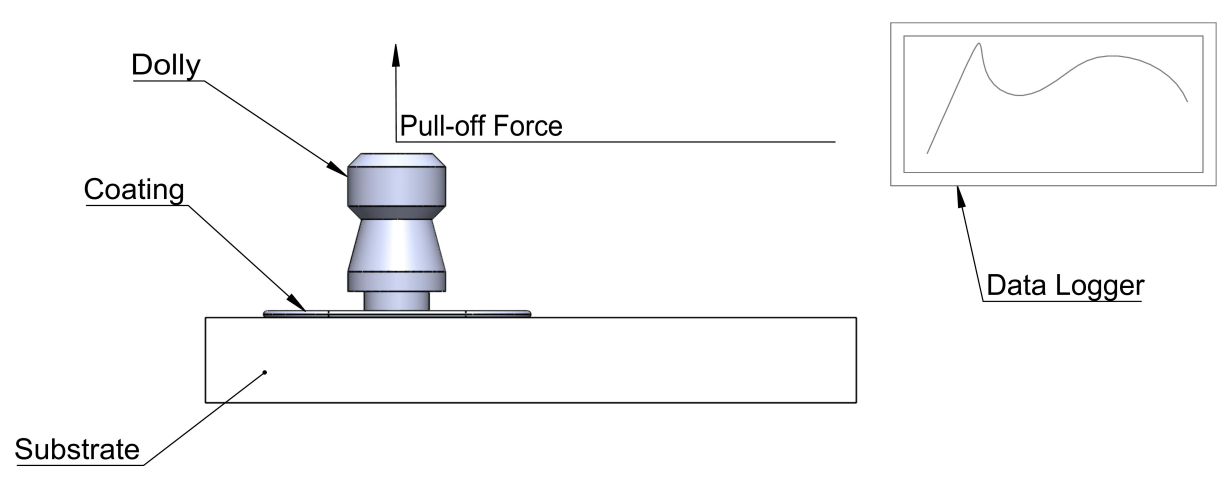

(b)

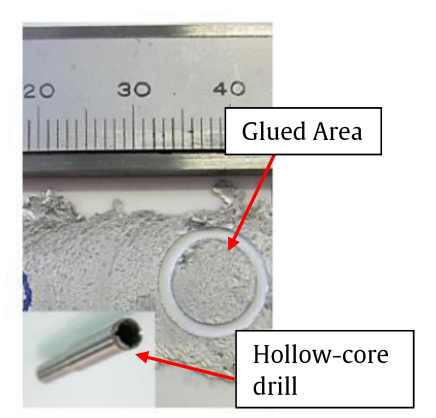

(c)

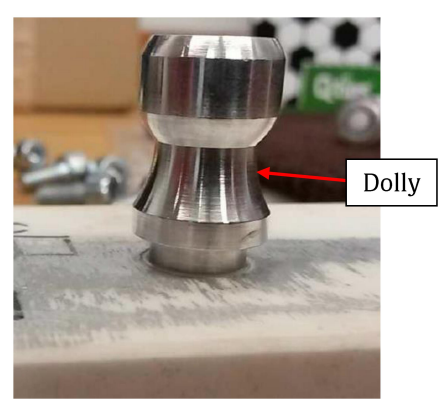

Fig. 6. Pull-off test: (a) schematic of arrangement, (b) the hollow core drill, and (c) the dolly [6, 15].

\subsection{Coating thickness}

For the measurement of the coating thickness a non-contact laser scanning microscope (Keyence Co., JPN, Model: VK-X 100) was used. By acquiring point-by-point mapped images (i.e. from the vantage of looking down upon and normal to the surface) which have been reconstructed with aid of computer, a three-dimensional model can be obtained. This model can be sliced at a desired position to get a surface profile of the coating. Figure 7(a) shows the side-section of a coated substrate with marked cross-section profile path and Figure $7(\mathrm{~b})$ shows the measured surface profile 
as a sliced view. As stated by Vitanov and Voutchkov [27] and Gandra et al. [7] the undercut at the sides of the coating is an inherent feature of the process. This unbonded area which shows a marked change in the cross sectional profile was excluded when measuring the coating thickness (Figure 7(b)).

(a)

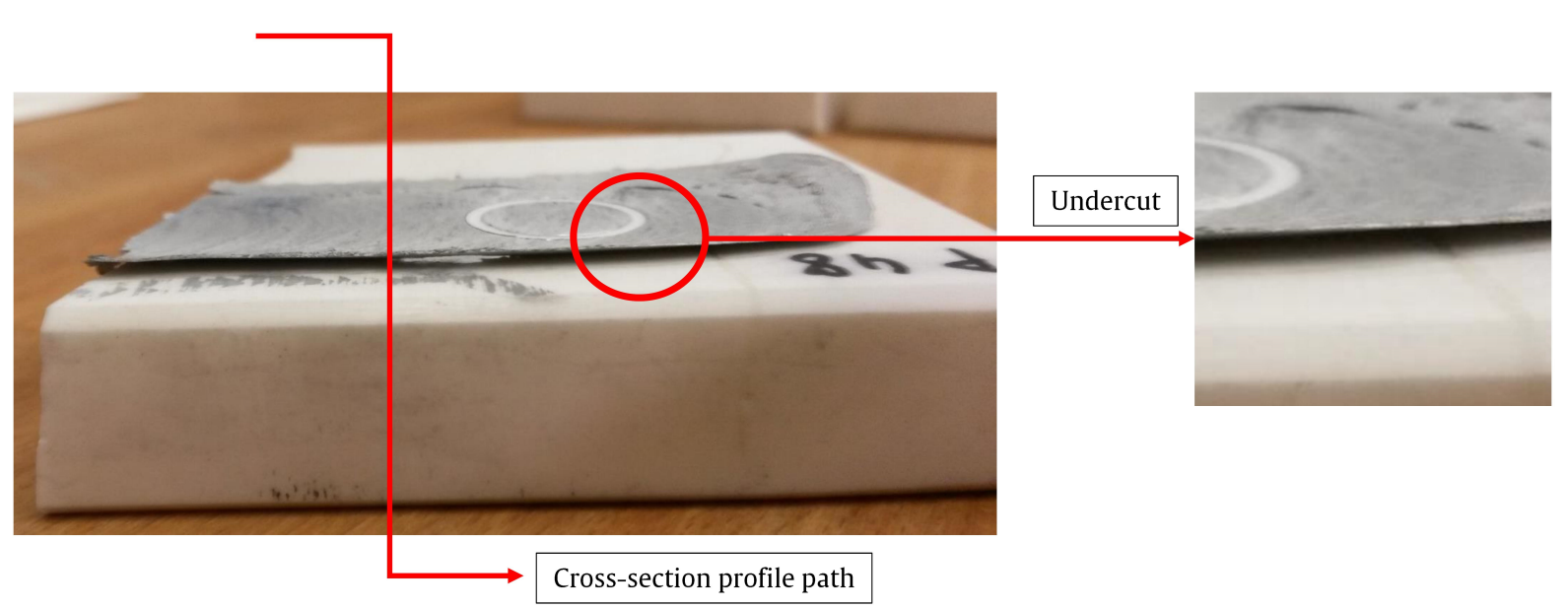

(b)

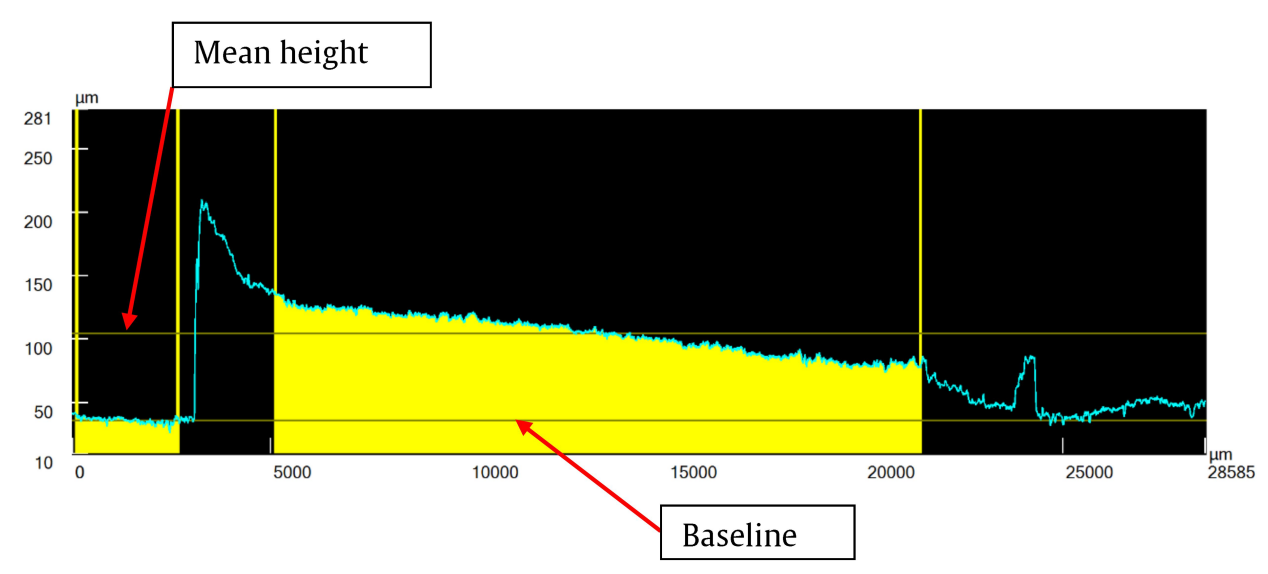

Fig. 7. Profiles of coated specimen: (a) Side-section, and (b) cross-section [6].

The uncoated area at the left side of the profile 'slice' was used as a baseline (datum). The peaks at the left and right corners were cut off by highlighting the area in-between. The measurement software then calculated the mean height by dividing the surface area by the area length.

\subsection{Design of experiments (DOE)}

The objective of the experiments conducted in this work was to identify the key factors and the interactions which effect bonding strength and thickness of the coating material on the substrate. 
In the work of Vitanov et al. [28], three factors were identified as being important: axial force (A), rotation speed (B) and substrate traverse speed (C).

The thermal shock sensitivity of the alumina substrate represents a major challenge. To mitigate the detrimental effect that thermal shock causes when stressing the material, a fourth factor was considered; namely, preheat temperature (D).

Based on the nature of the problem and the number of factors to be studied, a classical full factorial design with two levels was chosen. The total number of experiments $\mathrm{N}$ can be determined by the following equation [29]:

$$
N=\left(N_{k}+N_{c}\right) \cdot r
$$

For a two-level full factorial design, the equation for $\mathrm{N}_{\mathrm{k}}$ for $\mathrm{k}$ factors is:

$$
N_{k}=2^{k}
$$

To improve the chance of detecting significant effects among process variation and to obtain an accurate estimate of experimental error a replication factor $r$ is needed. To validate the linearity of the $2^{\mathrm{k}}$ factorial design centre points have been added. Centre points are additional experiments where the factors are set between the low and high values. The required centre points can be calculated with:

$$
N_{c}=k-1
$$

A total of 57 samples consisting of 4 factors and 3 replications have been tested for their bonding strength and coating thickness. To validate the linearity of the full factorial design 3 centre points have been added. To evenly distribute the effect of noise, randomisation was applied (i.e. in an attempt to ensure that points do not deviate markedly from the regression line).

For the two-level factorial design selected Table I describes the values and levels of the parameters. 
Table I. Factors.

\begin{tabular}{|c||c|c|c|}
\hline Factors & Levels & & \\
\hline & low & central & high \\
\hline \hline rotational speed & $3000 \mathrm{rpm}$ & $4500 \mathrm{rpm}$ & $6000 \mathrm{rpm}$ \\
\hline traverse speed & $150 \mathrm{~mm} / \mathrm{min}$ & $225 \mathrm{~mm} / \mathrm{min}$ & $300 \mathrm{~mm} / \mathrm{min}$ \\
\hline preheating temperature & $150^{\circ} \mathrm{C}$ & $250^{\circ} \mathrm{C}$ & $350^{\circ} \mathrm{C}$ \\
\hline axial force & $1246 \mathrm{~N}$ & $1869.5 \mathrm{~N}$ & $2493 \mathrm{~N}$ \\
\hline
\end{tabular}

\subsection{Thermal shock}

To determine the influence of the thermal shock on the bonding strength, a special piece of test equipment was designed and built which is shown in Figure 8(a). This apparatus allowed standardised specimens to be heated and then quenched with water.

The specimens produced were based on the geometry prescribed by the DIN EN 820-3 and DIN EN 843-1 standard and have a size of 45x4x3 mm. According to the DIN EN 820-3 standard the test equipment should consist of a temperature controlled oven, a suitable sample holder and a water bath with sufficient volume. It can be seen in Figure 8(b) the setup of equipment which permitted the specimens to be placed onto the sample holder, inserted into the furnace, heated up to the shock temperature and then quenched in the quench medium.

To determine the flexural strength of the specimens a four-point bending apparatus, in accordance with testing conventions specified in DIN EN 843-1, was designed and mounted into a load frame (ZwickRoell Co., Germany, Model: Z010). The specimens were placed onto the supporting pins (separation distance 40mm) and a loading force was applied by a stamp and two loading pins (separation distance 20mm) until failure occurs (Figure 8(c)]. 
Fig. 8. Thermal shock tests: (a) equipment,(b) sample holder, and (c) four-Point bending test schematic.

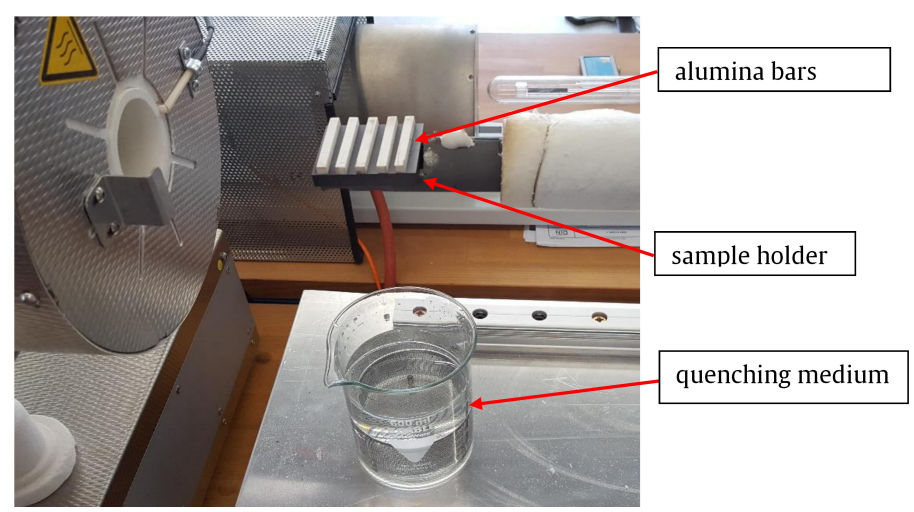

(c)

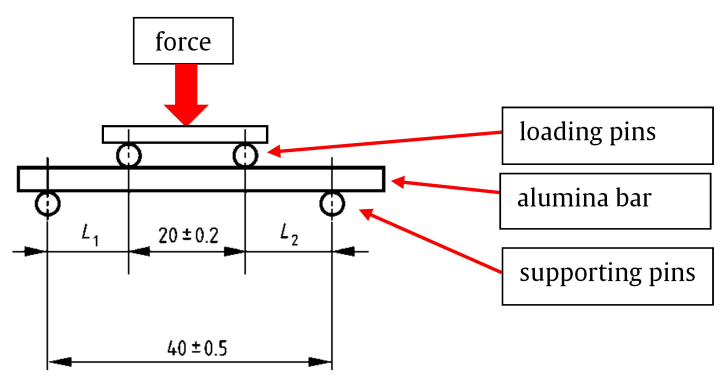

(a)

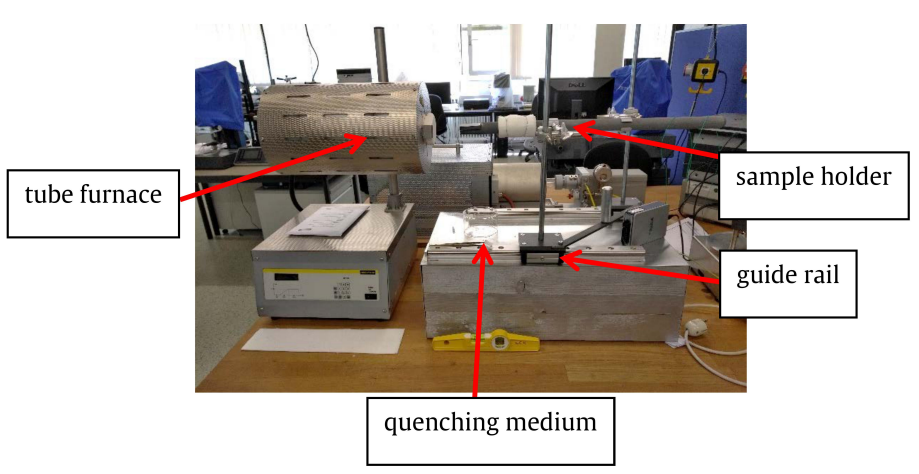

(b) 


\section{Results and Discussion}

\subsection{Coating Thickness}

In an attempt to abbreviate the tables and equations in this section, a parametric nomenclature (i.e. rotational speed (n), traverse speed (f), preheating temperature $(T)$, axial force $(\mathrm{p})$ ) has been used. The results of the DOE analysis for the coating thickness can be seen in Table II The significance of a given parameter can be evaluated by its Probability-Value (P-Value). The P-Value represents the strength of evidence against the null hypothesis $\mathrm{H}_{0}$ [30], which in this case is a measure of the significance of the effects of the parameters chosen. According to Du Prel et al. [31] a significance limit must be specified in order to decide if $\mathrm{H}_{0}$ can be rejected. For this model a significance $\alpha$ of 0.05 was chosen. All parameters with a $\mathrm{P}$-value higher than 0.05 have no significant effect on the response. The confidence level is related to $\alpha$ and can be calculated by $\mathrm{C}=(1-\alpha)[32]$. This means that there will be $95 \%$ confidence in the accuracy of the result.

Looking at Table $\Pi$ it can be seen that the factors $\mathrm{n}, \mathrm{f}, \mathrm{p}$ and the 2 -Way interaction $\mathrm{n} \cdot \mathrm{f}(\mathrm{P}<0.001)$ and $n \cdot p(P=0.014)$ have a significant effect on the coating thickness.

After identifying the main effects which influence the coating thickness, a simple regression model was developed. By using only the significant factors the prediction model for the coating thickness is as follows:

$$
\begin{aligned}
\text { coating thickness }=-92.5+0.0351 \cdot n+ & 0.307 \cdot f \\
& -0.0152 \cdot p-0.000126 \cdot n \cdot f+0.000010 \cdot n \cdot p
\end{aligned}
$$

On that note, a revised table has been constructed, Table III. whereby only the significant factors have been included.

For a proper statistical analysis, the experimental data must be checked for a normal distribution. This can be done by constructing a Normal Probability Plot (NPP) of the residuals. The residual is the vertical distance from one data point (observed value) to the regression line (predicted value) of the constructed model. Antony [29] states that for a normal distribution the residuals must fall approximately on a straight line. Figure 9 shows the NPP of residuals.

It can be seen that for the most part points do not deviate markedly from the regression line. This indicates that the distribution of the data can be classed as normal. 
Table II. Analysis of variance for coating thickness.

\begin{tabular}{|c||c|}
\hline Analysis of Variance & \\
\hline Source & P-Value \\
\hline \hline Linear & $<0.001$ \\
\hline $\mathrm{T}$ & 0.860 \\
\hline $\mathrm{n}$ & $<0.001$ \\
\hline $\mathrm{f}$ & $<0.001$ \\
\hline $\mathrm{p}$ & $<0.001$ \\
\hline 2-Way Interactions & 0.005 \\
\hline $\mathrm{T} \cdot \mathrm{n}$ & 0.481 \\
\hline $\mathrm{T} \cdot \mathrm{f}$ & 0.495 \\
\hline $\mathrm{T} \cdot \mathrm{p}$ & 0.502 \\
\hline $\mathrm{n} \cdot \mathrm{f}$ & $<0.001$ \\
\hline $\mathrm{n} \cdot \mathrm{p}$ & 0.014 \\
\hline $\mathrm{f} \cdot \mathrm{p}$ & 0.956 \\
\hline Curvature & 0.115 \\
\hline \hline Lack-of-Fit & 0.227 \\
\hline Model Summary & \\
\hline & $\mathrm{R}-\mathrm{sq}$ \\
\hline & $81.32 \%$ \\
\hline & \\
\hline & \\
\hline & \\
\hline & \\
\hline
\end{tabular}


Table III. Analysis of variance for coating thickness with only significant factors.

\begin{tabular}{|c||c|}
\hline Analysis of Variance & \multicolumn{1}{|c|}{} \\
\hline Source & P-Value \\
\hline \hline Linear & $<0.001$ \\
\hline $\mathrm{n}$ & $<0.001$ \\
\hline $\mathrm{f}$ & $<0.001$ \\
\hline $\mathrm{p}$ & $<0.001$ \\
\hline 2-Way Interactions & 0.005 \\
\hline $\mathrm{n} \cdot \mathrm{f}$ & $<0.001$ \\
\hline $\mathrm{n} \cdot \mathrm{p}$ & 0.011 \\
\hline Curvature & 0.098 \\
\hline \hline Lack-of-Fit & 0.947 \\
\hline \hline Model Summary & \\
\hline & $\mathrm{R}-\mathrm{sq}$ \\
& $79.15 \%$ \\
\hline
\end{tabular}




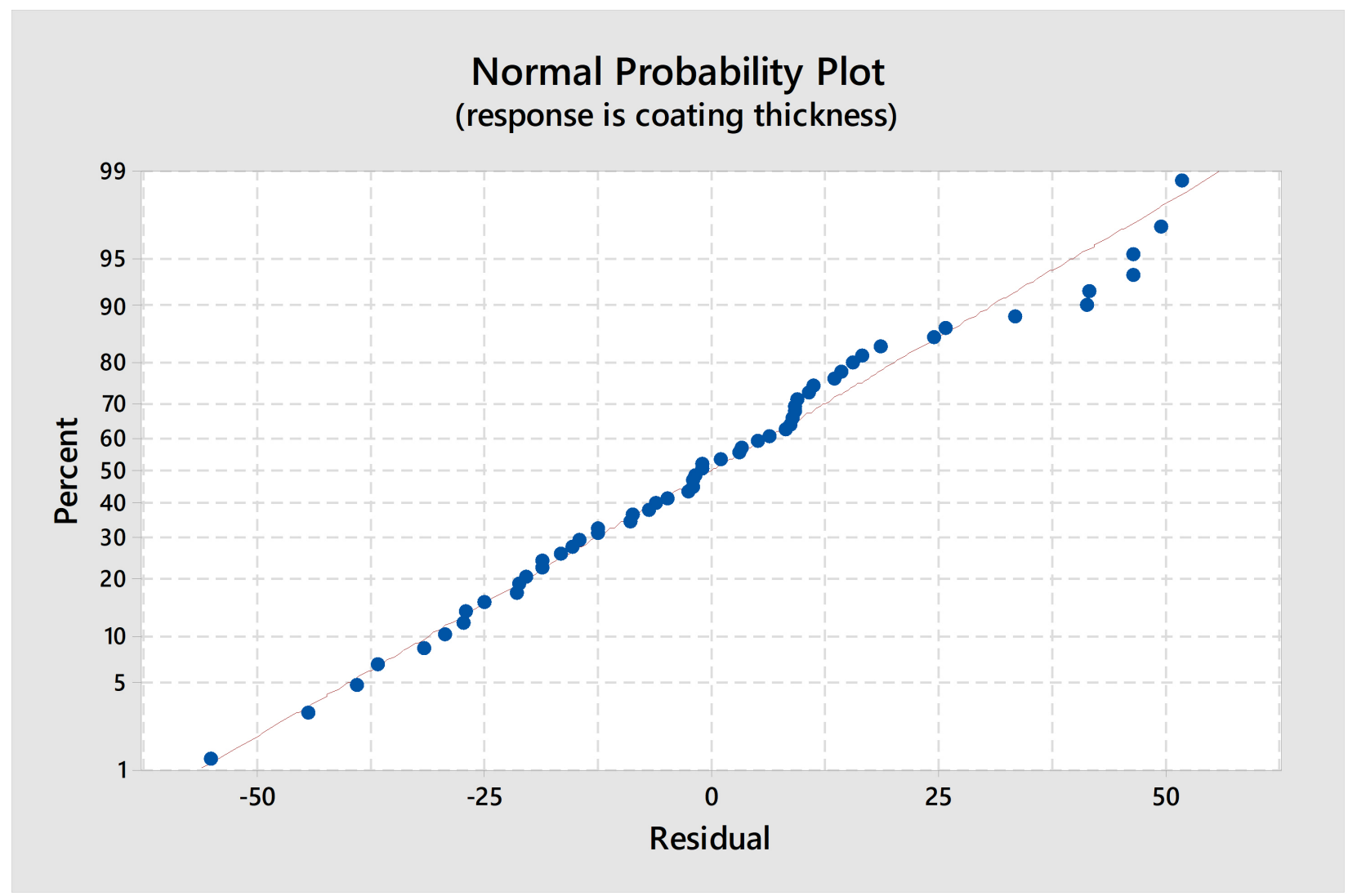

Fig. 9. Probability plot for coating thickness. 
A response of interest was the thickness of the coating material deposited on the substrate. It was important to analyse possible two factor interactions and their corresponding effects. Figure 10 shows the interaction plots for the four parameters. The minimum and maximum values are indicated by a blue and a green line, respectively. The coating thickness is plotted on the vertical axes in $\mu \mathrm{m}$ and various process parameters are plotted on the horizontal axes. Twelve interactions with four parameters are plotted each of which can be analysed by the slope and distance between the extreme points. The greater the difference in slope between the line pairs, the higher the degree of interaction [29]. If the lines are parallel, there is no interaction between the parameters.

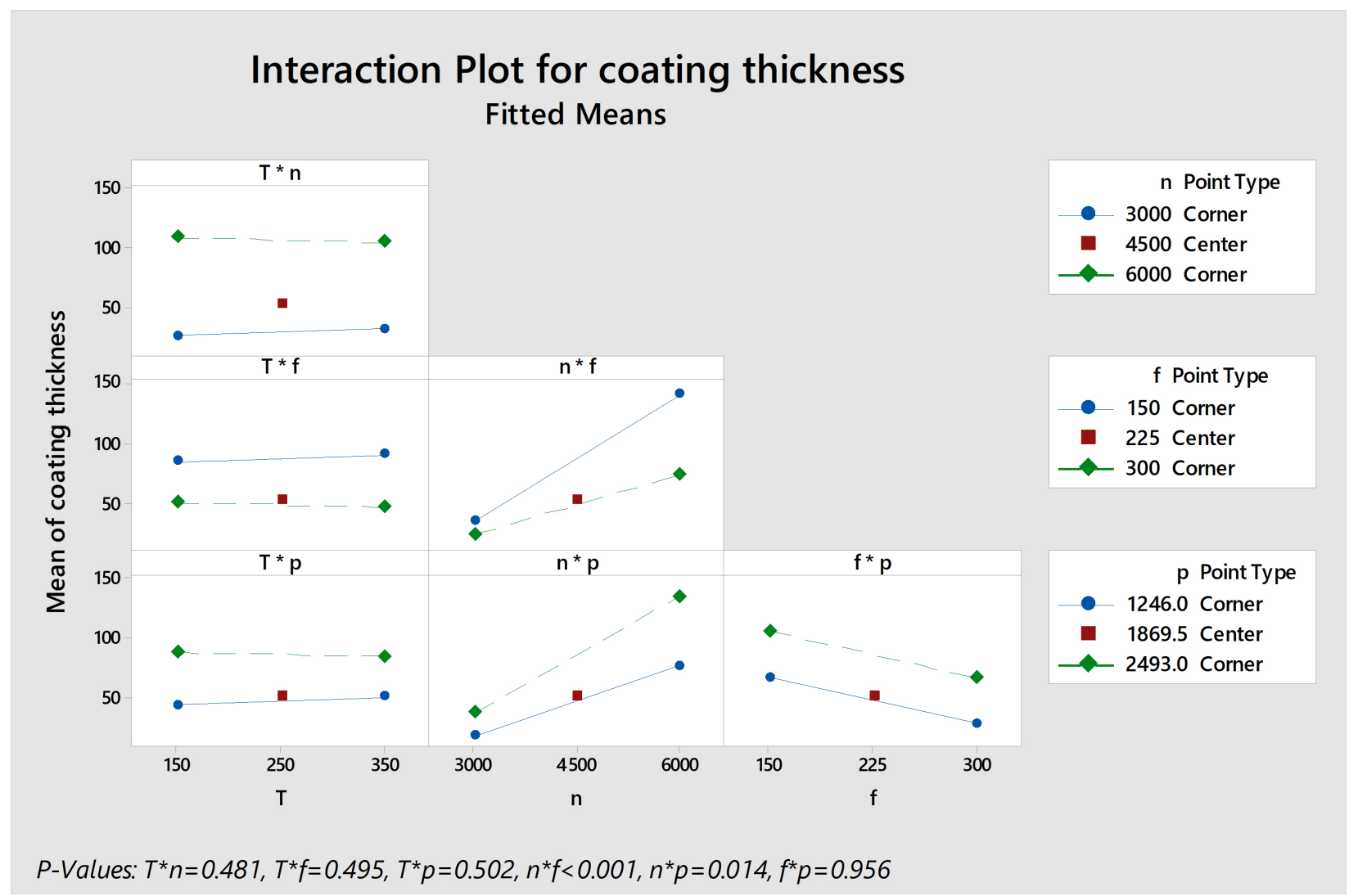

Fig. 10. Interaction plots for coating thickness, $[\mu \mathrm{m}]$.

Turning attention to the temperature interaction plots. Now, during the friction surfacing the temperature at the interface reaches a plateau at approximately $580^{\circ} \mathrm{C}$ (see Figure $13(\mathrm{a}$ ) and Figure 13(b)]. It was described in works on friction surfacing by both Pereira et al. [33] and Vilaça [34] that the viscoplastic region of the softened rod is pressed against the substrate which leads to a bonding process and deposition of rod material. The substrate temperature is not significant at this point of the process in relation to the coating thickness. 
Further analysis of the interaction graph between rotational speed and traverse speed reveals that the coating thickness is highest when the combination of rotational speed is kept at a high rate and the traverse speed at a low level. Also, the interaction graph between rotational speed and axial force clearly indicates that the coating thickness is at a maximum when the rotational speed and axial force are kept at high.

This is contrary to what is published concerning the friction surfacing of metals, where the coating thickness decreases with increasing rotational speeds [5]. This process behaviour could be explained by the increase of frictional area at the inner diameter of the rod. When removing the core material from the rod by drilling a hole at the centre, not only is a flash formed on the outside of the rod but also on the inside. This inner flash increases the contact area of the rod. At higher rotational speeds this inner flash might act as an additional friction surface and increase the plasticised layer being generated, thus increasing the coating thickness.

As seen in Table III the calculated lack-of-fit P-Value is 0.947 and the R-squared value is 79.15\%; terms which determine the accuracy of a regression model. The lack-of-fit P-Value indicates if the regression model fits the underlying data with the specified $\alpha$ level and if the assumed relationship in the model is reasonable or not. The R-squared value indicates how much of the variation in the response variable is accounted for by the linear model [35]. In this case the two values may be judged to be high which indicates that the generated model fits the data satisfactorily and that the friction surfacing process is fairly stable in regard to the coating thickness, i.e. it is not sensitive to parametric change.

\subsection{Bonding Strength}

Table IV shows the P-Values of the bonding strength. It can be seen that only the factors $\mathrm{n}$ and p have a significant effect on the bonding strength as demonstrated by their low P-Values.

In this case the predicted model containing only the significant factors for the bonding strength is as follows:

$$
\text { bonding strength }=54.67-0.003157 \cdot n-0.00554 \cdot p
$$

Table $\mathrm{V}$ shows the adjusted variance analysis.

Looking at the probability plot (Figure 11) it is evident that the distribution of the data is again normal. 
Table IV. Analysis of variance for bonding strength.

\begin{tabular}{|c|c|}
\hline Analysis of Variance & \\
\hline Source & P-Value \\
\hline Linear & 0.007 \\
\hline $\mathrm{T}$ & 0.618 \\
\hline 3 & 0.003 \\
\hline $\mathrm{f}$ & 0.996 \\
\hline $\mathrm{p}$ & 0.022 \\
\hline 2-Way Interactions & 0.550 \\
\hline$T \cdot n$ & 0.742 \\
\hline $\mathrm{T} \cdot \mathrm{f}$ & 0.367 \\
\hline $\mathrm{T} \cdot \mathrm{p}$ & 0.402 \\
\hline$n \cdot f$ & 0.714 \\
\hline$n \cdot p$ & 0.138 \\
\hline$f \cdot p$ & 0.341 \\
\hline Curvature & 0.400 \\
\hline Lack-of-Fit & 0.591 \\
\hline \multirow[t]{2}{*}{ Model Summary } & \\
\hline & $\begin{array}{c}\text { R-sq } \\
35.61 \%\end{array}$ \\
\hline
\end{tabular}

http://mc.manuscriptgeptral.com/(site) 


\section{Normal Probability Plot (response is bonding strength)}

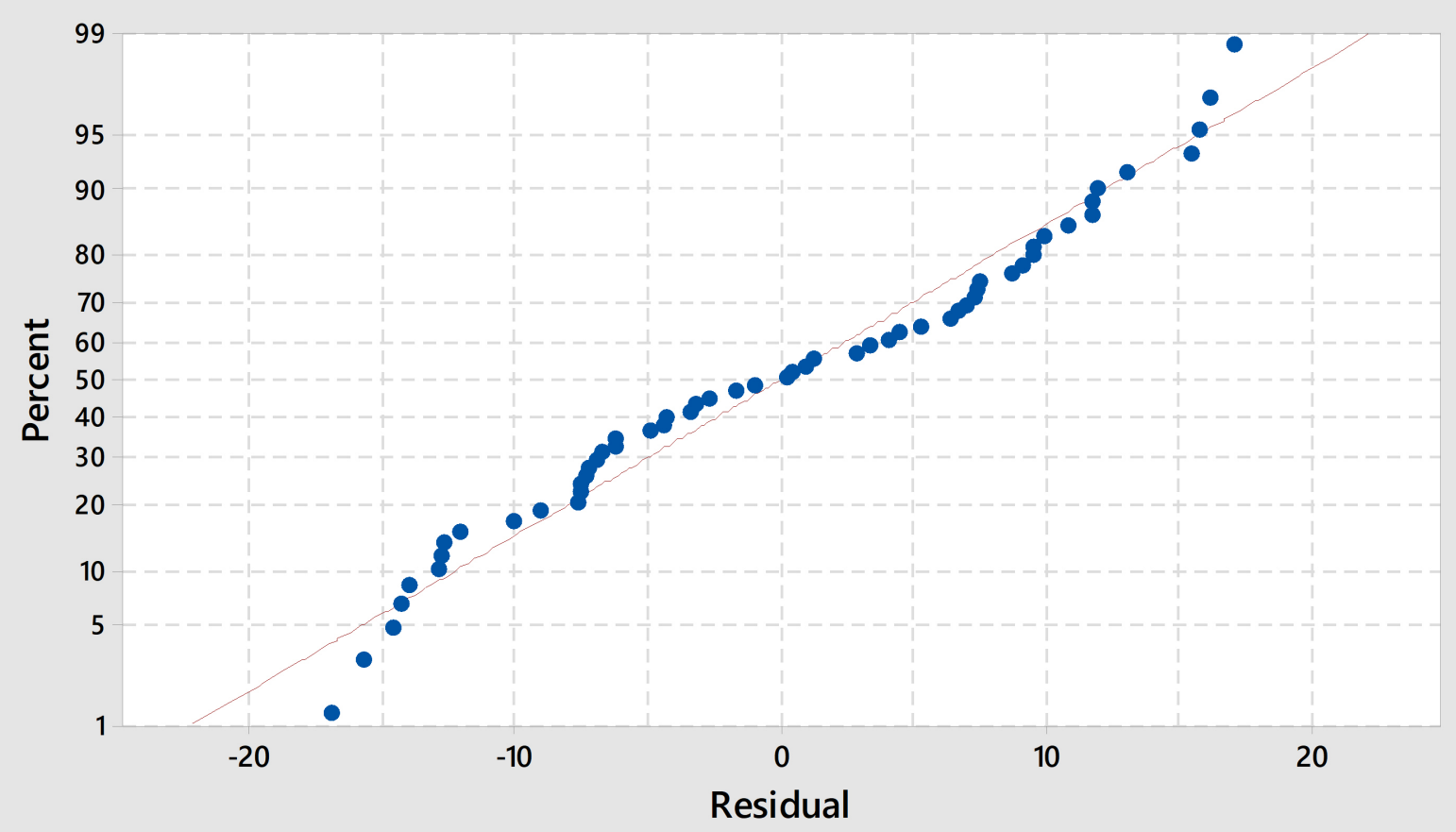

Fig. 11. Probability plot for bonding strength. 


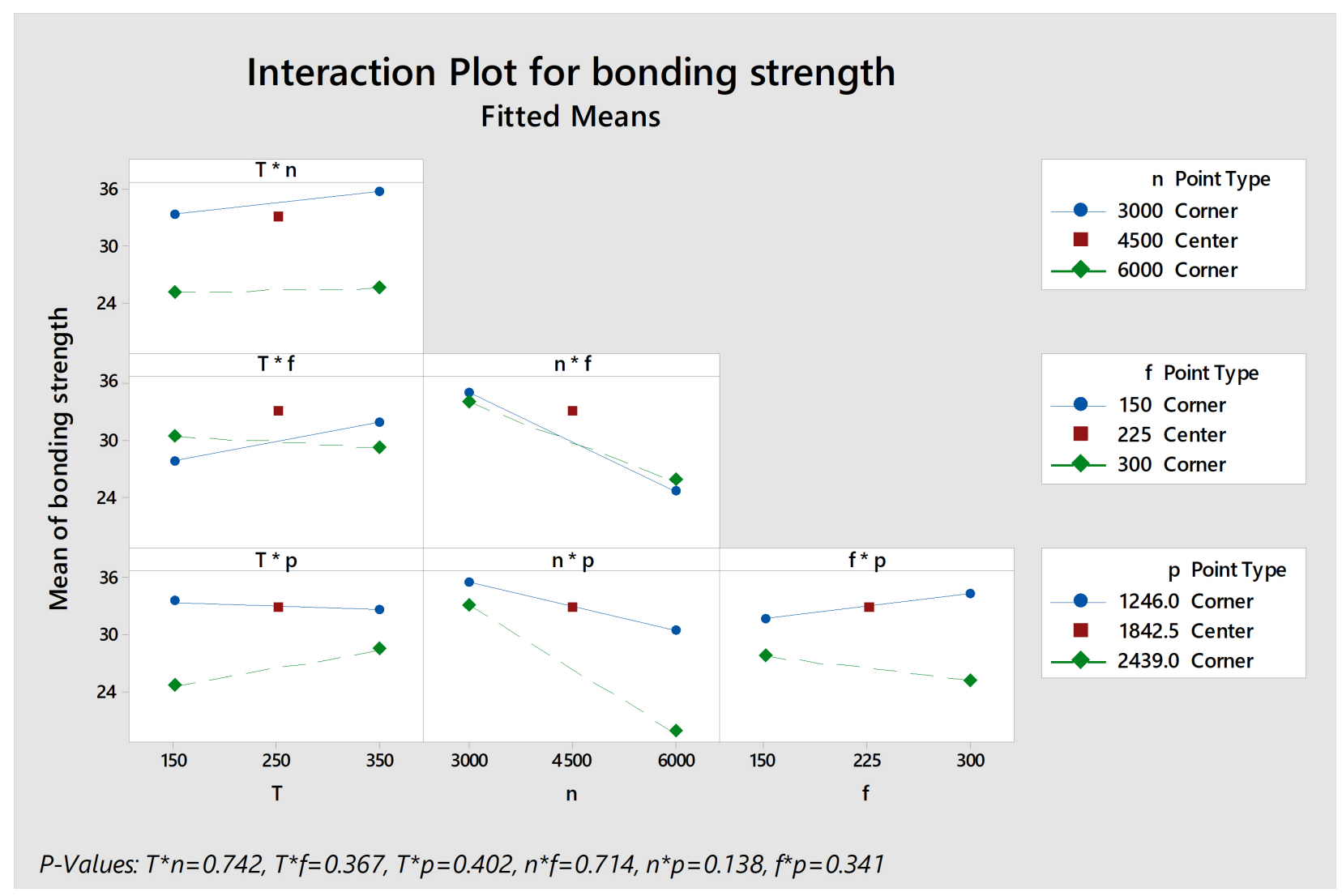

Fig. 12. Interaction plots for bonding strength, [MPa]. 
Figure 12 illustrates the interaction between all process parameters. Analysing the interaction plots, the largest interaction occurs between rotation speed $\mathrm{n}$ and force $\mathrm{p}$. At low rotation speeds and force the interaction is low, but increasing the value of the parameters led to a negative slope of the lines. The second significant interaction is between the feed rate and force. Increasing the traverse speed at low force leads to higher bonding strengths, but by also increasing the force the bonding strength decreases. All interactions with rotational speed indicate a negative slope of the lines. This detrimental effect can also be seen at the interaction plots that include the axial force (see lower half of Figure 12). This can probably be attributed to the increase in substrate material stress and thus crack initiation on the surface of the substrate which will be analysed and discussed in Section 3.4. The model also must be evaluated to assess if it represents the underlying data accurately and this can be seen in the lack-of-fit P-Value of 0.554, which indicates that data fitted the model satisfactorily. However, looking at the model summary it shows an R-squared value of $24.52 \%$ which is very low. This indicates that other factors are affecting the behaviour of the response that are not included in the model. One factor will be cracking of the substrate surface during the process, discussed later: thus, the model should be interpreted with caution.

\subsection{Thermal Analysis}

To get a better understanding of the bonding process, measuring the heat generated at the contact interface is critical. From this information diffusion processes and phase formation can be analysed. For this purpose, alumina plates were prepared with slots and four thermocouples were embedded near the friction surface. As stated by Gandra et al. [4] the generated heat at the friction zone is forming a consistent quasi-liquid-layer between the rod and the surface of the substrate. This quasiliquid-layer is deposited on to the specimen and forms the solid coating. The rubbing interface is transferred above the coating and generates the heat for the process. The prepared slots and embedded thermocouples do not influence the friction surfacing process and the deposition of the coating material. The setup can be seen in Figure 5.

Figure 13(a) and Figure 13(b) shows the thermal plot of the four thermocouples (tc_1 to tc_4) of two specimens coated at $\mathrm{n}=3000 \mathrm{rpm}$ and $6000 \mathrm{rpm}$ during the friction surfacing process. For both the thermal plots the traverse speed was set to $200 \mathrm{~mm} / \mathrm{min}$, preheating temperature to $300^{\circ} \mathrm{C}$ and axial force to $2493 \mathrm{~N}$.

It can be seen (Figure 13(b) that the interface temperatures can reach up to approximately $580^{\circ} \mathrm{C}$. At such temperatures and with the high surface pressure created during the process, if a 
(a)

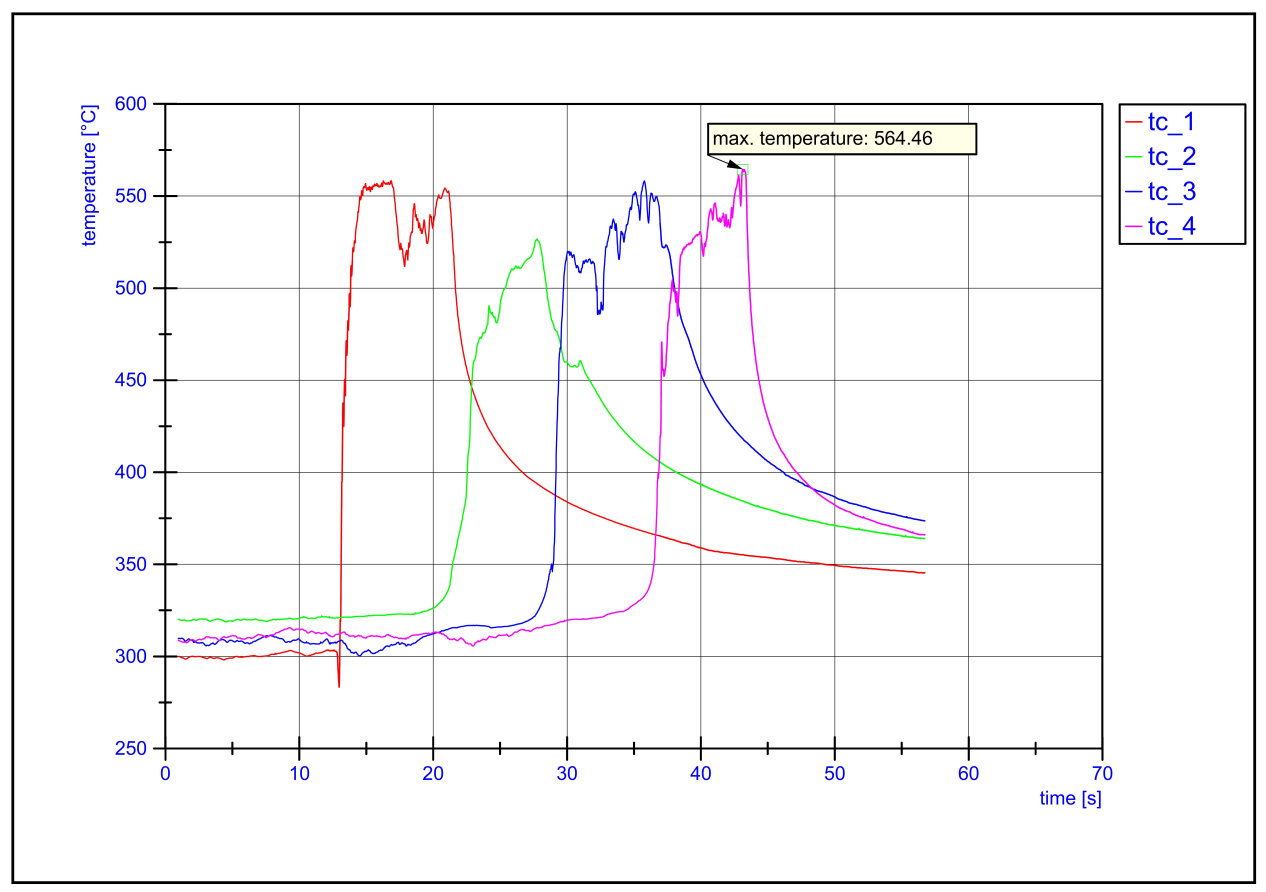

(b)

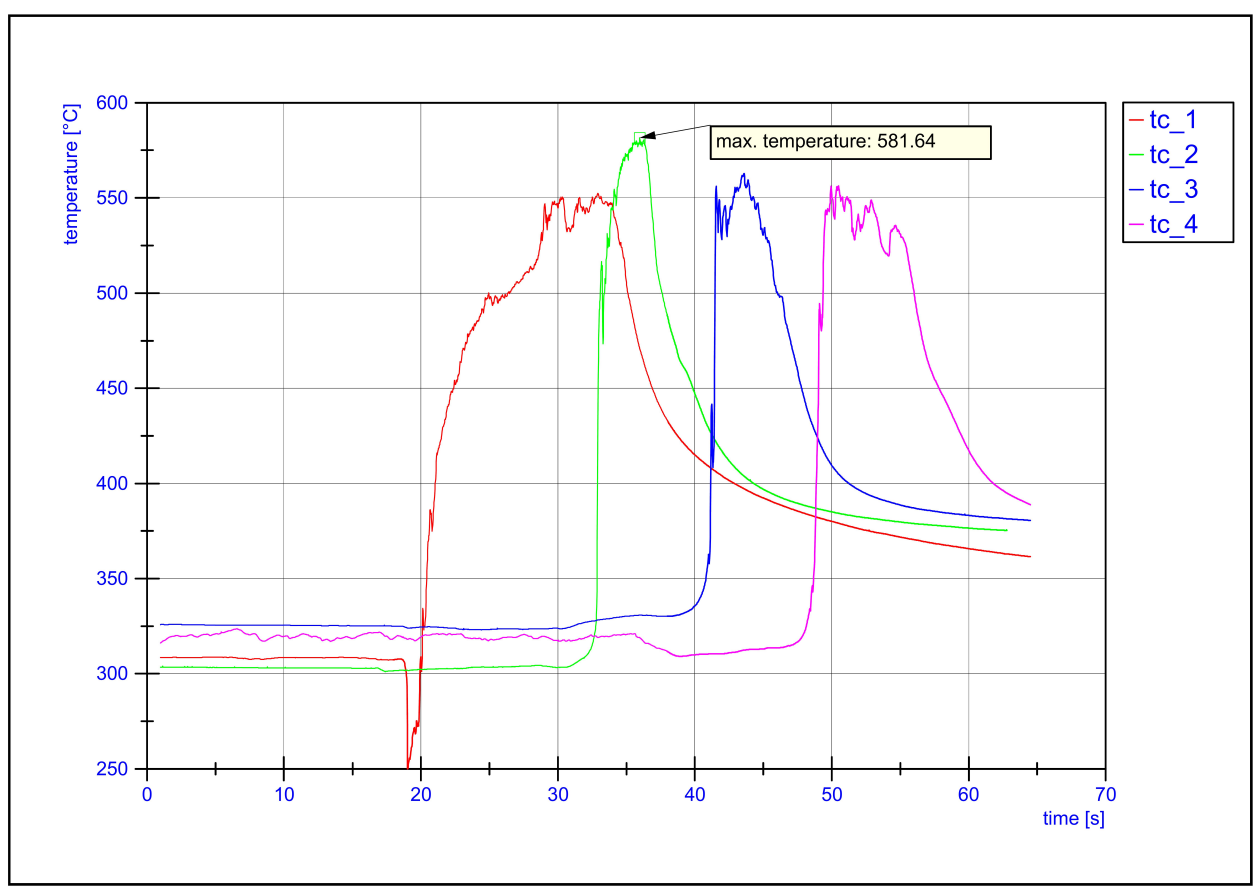

Fig. 13. Thermal plots at a spindle rotational speed of (a) 3000rpm and (b) 6000rpm.

http://mc.manuscriptgentral.com/(site) 
phase-diagram of the $\mathrm{Al}_{2} \mathrm{O}_{3}-\mathrm{MgO}$ systems is considered, the probability of forming inter-metallic compounds exists. In their work on diffusion bonding of alumina, Hosseinabadi et al. [36] states that interlayers and the formation of compounds can improve the bond strength of alumina joints. In friction stir spot welding, a strong linkage can be found between bonding strengths and the thickness of an intermetallic compound layer which can improve the bonding strength of the joint [37]. However, as Choi et al. [37] describes in his work about formation of intermetallic compounds in $\mathrm{Al}$ and $\mathrm{Mg}$ alloy interfaces, care is necessary regarding the thickness of these layers; thicker layers will serve to decrease the strength.

\subsection{Thermal shock}

By optically examining the specimens and the corresponding pull-off dollys after strength testing and classifying the tear-off interfaces, it was noticed that approximately $60 \%$ failed within the alumina surface. Figure 14(a) shows the dolly of specimen P54 which had the highest bonding strength of $47.79 \mathrm{MPa}$ and additionally the greatest amount of alumina break-out remaining on the dolly.

(a)

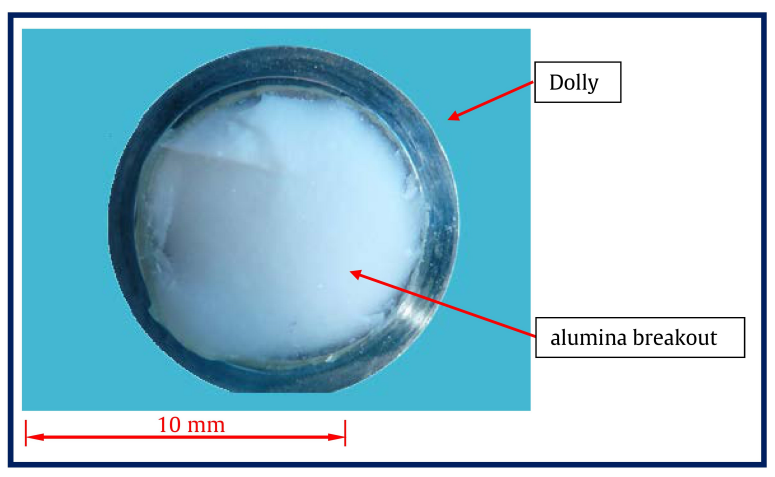

(b)

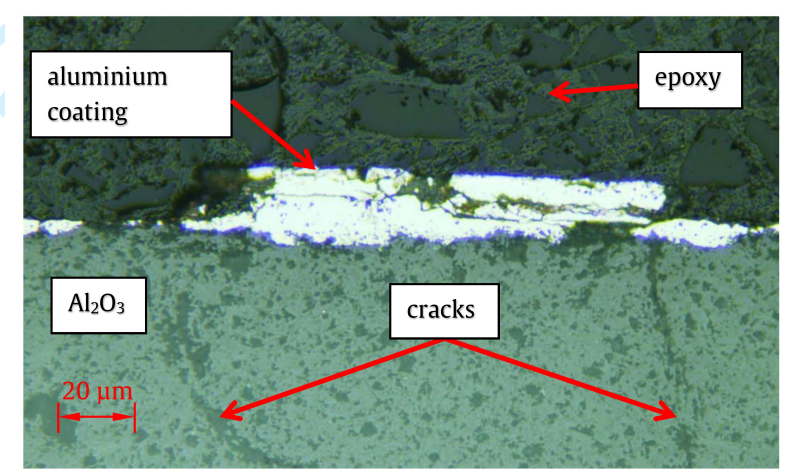

(c)

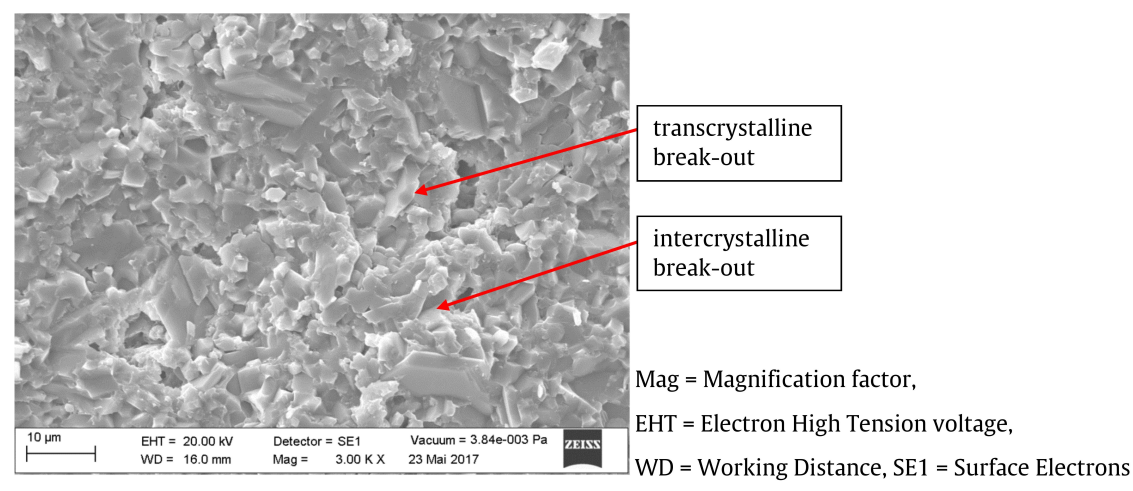

Fig. 14. (a) Dolly with alumina breakout [6], (b) substrate cross-section [15], and (c) break-out characteristics. 
The break-out was seen to emanate from micro-cracks beneath the surface, which could be attributed to the process forces and high temperatures. Figure 14(b) shows a polished cross section of the specimen P19. This specimen clearly shows the micro-cracks induced.

Due to the high coating temperatures the coated specimens tended to crack. This phenomenon was observed for all parametric variations and cannot be attributed to a specific parameter set. Further investigation showed evidence of inter-crystalline and trans-crystalline surface breakouts, see Figure 14(c), This is connected to the thermal shock resistance and high thermal expansion coefficient of the alumina. The rapid change in temperature during the coating process results in a thermal expansion of the surface while the core material of the substrate remains relatively cold. The relative change in material volumes (differential expansion/contraction) induced stresses and producing a weakening of the grains and their boundaries [18].

As can be seen in Figure 15 the average flexural strength of the alumina bars at $20^{\circ} \mathrm{C}$ was recorded to be $258 \mathrm{MPa}$ (minimum and maximum values shown with black bars). The strengthdrop is small for a quenching temperature difference of $230 \mathrm{~K}$. Increasing the temperature further, the flexural load required to cause fracture decreases markedly to approximately 66MPa. This is also in line with the findings of Auerkari [18] in which a critical thermal shock temperature $\Delta \mathrm{T}$ of $180 \mathrm{~K}$ was measured. Looking at Figure 15 it is clear that the temperatures that the experiments were conducted (bounded by the blue box) are within the critical $\Delta \mathrm{T}$ region for the alumina (red box). These results suggested that the damage induced by thermal shock leads to a failing of the specimens beneath the coating in the substrate itself.

To reduce the thermal shock induced the specimens can be preheated to a higher temperature. Trials have been conducted where the preheating temperature was increased to $450^{\circ} \mathrm{C}$, so reducing the thermal shock to approximately $130 \mathrm{~K}$. However, this led to a reduction of the bonding area and reduced bonding of the coating on the substrate. According to Gandra et al. [4] the quasi-liquid layer forms on the contact plane and continuously transforms to solid during deposition. A reason for the reduction in bonding strength could be due to the increase of melt content in the quasi-liquid phase of the aluminium, which causes a sliding film to form. This sliding film impairs the adhesion of the coating. Because the bonding of the coating to the substrate is crucial, this approach was assessed as ineffective and not pursued further. 


\subsection{Microscopy and EDX analysis}

In contrast to friction surfacing of ceramics with metals, which has received very little attention by researchers, friction welding of ceramics with metals is well known. Although the publication from Uday and Ahmad-Fauzi [38], regarding friction welding between aluminium with alumina detailed that intermetallic compounds were detected, this phenomenon was not observed in this study. Figure 16 shows the interface of the aluminium coating on the alumina substrate. The geometry of the aluminium coating at this junction takes the form (profile) of the substrate surface; i.e. it is an imprint. 


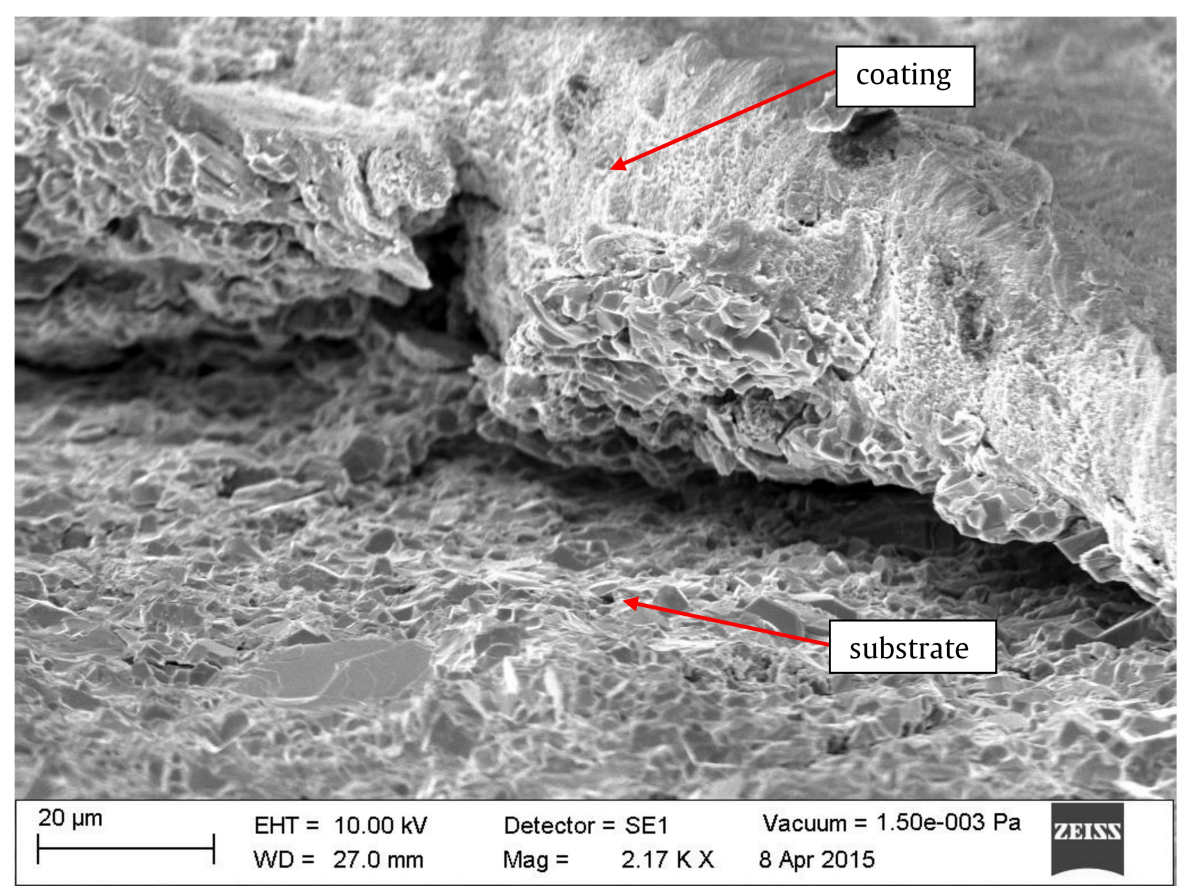

Fig. 16. SEM image of coated substrate surface.

To further investigate the mechanical interlocking, the dolly surfaces and corresponding specimens have been analysed in more detail. This involved the surface structure being scanned with a 3D laser scanning microscope (Keyence Co., JPN, Model: VK-X 100). Figure 17(a) shows the 3D surface profile of the alumina substrate after removing the dolly. Whereas Figure $17(\mathrm{~b})$ shows the surface profile of the material on the removed dolly. 
(a)

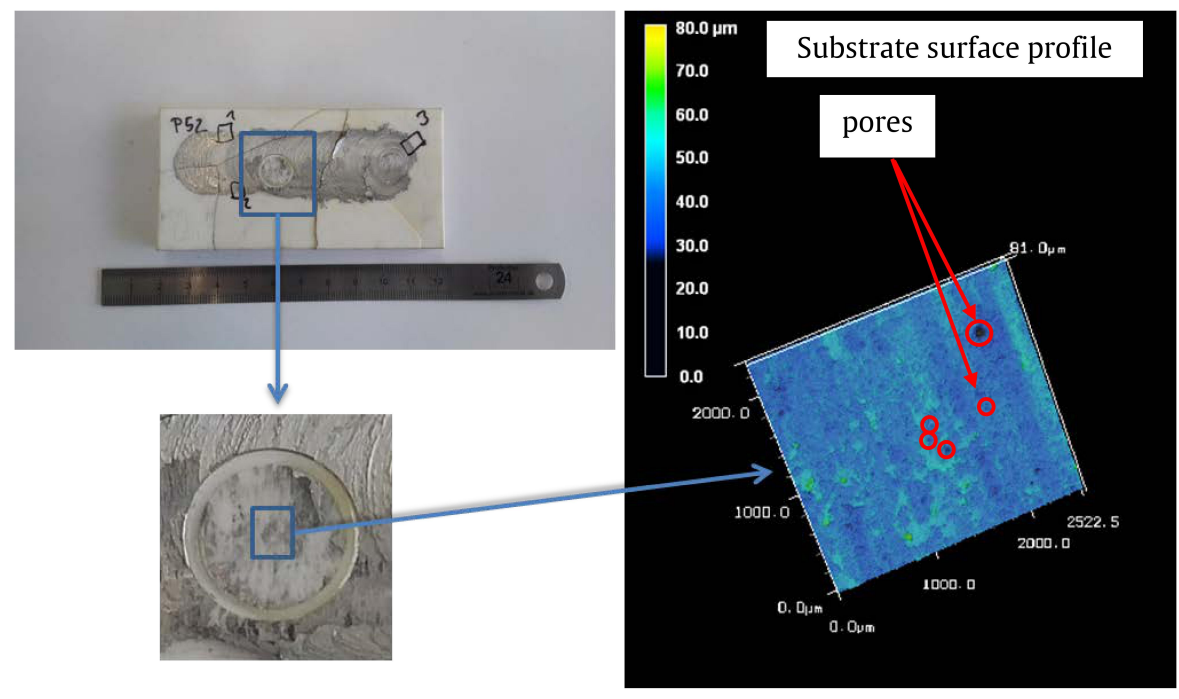

(b)

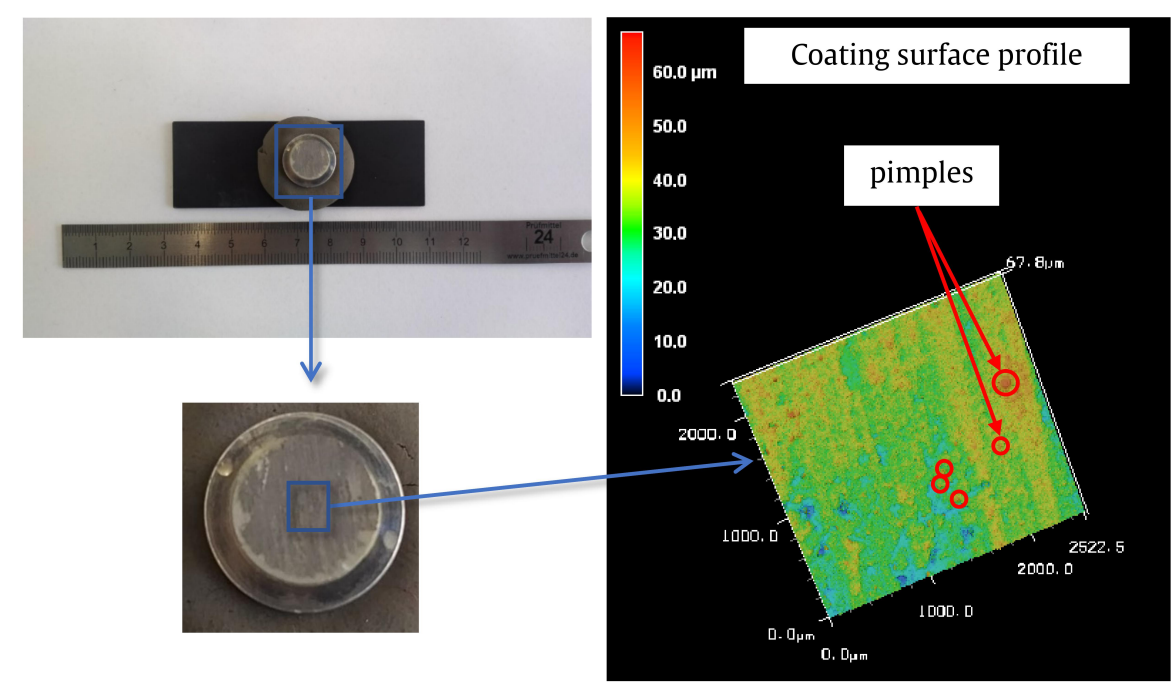

Fig. 17. 3D surface profile of (a) substrate, and (b) pulled-off coating.

Comparing these two profiles (Figure 17 ) indicates that the aluminium coating, in its viscoplastic state, is flowing into the pores and builds a negative imprint of the surface; thus forming a mechanical bond by interlocking.

Further investigation of the interface has been conducted. By mapping, i.e. combining a SEM image with EDX data, small regions associated with particular elements can be identified. Figure 18 shows a SEM image (left side) and a mapped image of the coating interface (right side). 
(a)

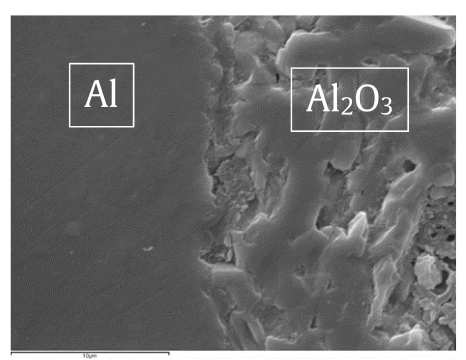

(b)

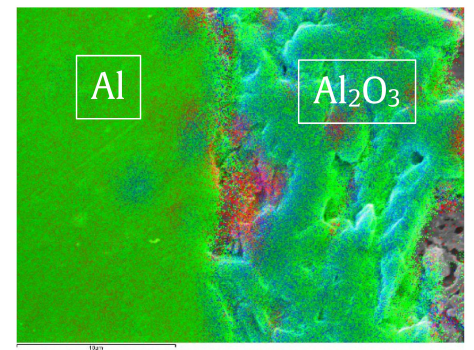

red: Mg, blue: O, green: Al

Fig. 18. SEM image of the interface: (a) without processing, and (b) mapped image.

The mapped image reveals a region of magnesium accumulation at the interface (red). On closer examination it is obvious that these red accumulations are widespread on the alumina side of the specimen; however, not on the aluminium itself. This indicates that these do not originate from the surfacing process, but existed beforehand. On further analysis of the alumina mixture it became apparent that magnesium oxide $(\mathrm{MgO})$ was used as an additive in the sintering process. These additives are used for lowering the sintering temperature and accumulate at the grain boundaries during production [39]. Consequently, investigation of the interface shows no evidence of inter-metallic compounds, with the only evidence for a means of bonding at the interface through mechanical interlocking. Nevertheless, this mechanism alone cannot account for the bonding strength values realised (see Table VI).

To further assess the proportion of mechanical interlocking the surface of pulled dollys and corresponding substrates have been inspected. The most complete detachment of the coating from the substrate without alumina break-outs was observed for specimen P28. Figure 19(a) shows the scanned surface of dolly P28 and Figure 19(b) the alumina substrate. It can be seen that aluminium has been ripped out of the surface during the pull-off test leaving holes. The counterparts are stuck on the surface of the alumina substrate.

These left-overs form an interlock with the pores on the substrate and are responsible for a specific portion of the pull-off force. By using image processing software, namely imageJ [40] , the surface area of the left-overs can be measured and calculated. Figure 19(c) shows the scanned area of the dolly surface and Figure 19(d) the image processed in which the left-over areas are filtered.

Table VI shows the calculated area for the dolly with a diameter of $10 \mathrm{~mm}$, the measured area 
(a)

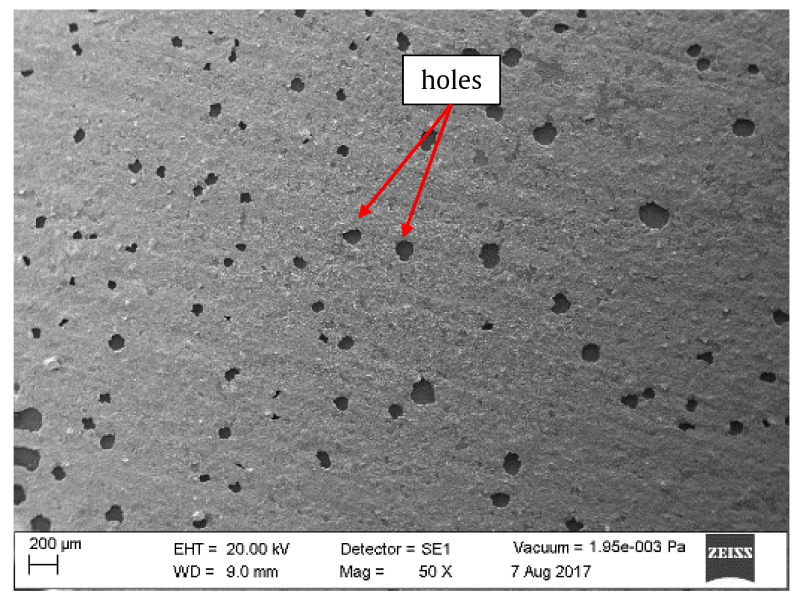

(c)

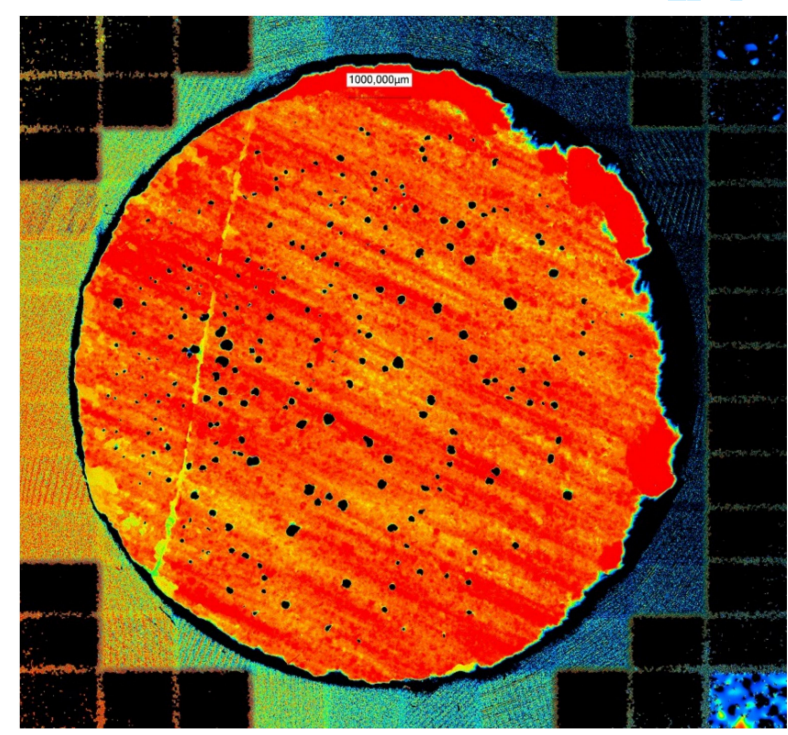

(b)

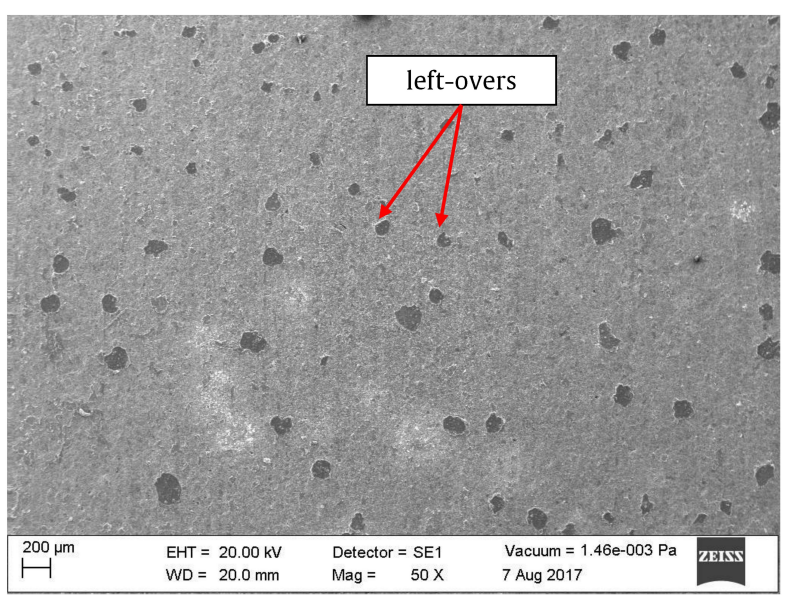

(d)

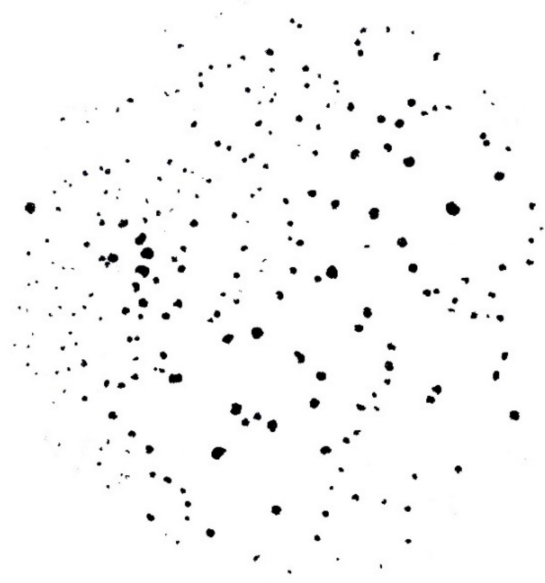

Fig. 19. Interlocked surface area: (a) dolly surface, (b) substrate surface, (c) dolly scanned area, and (d) image processed. 
of left-overs, the tensile strength of the coating material and the theoretical pull-off force. The mechanical interlocking portion can easily be calculated.

Table VI. Interlocking portion.

\begin{tabular}{|c||c|}
\hline area of dolly & $78.54 \mathrm{~mm}$ \\
\hline area of left-overs & $1.806 \mathrm{~mm}(2.3 \%)$ \\
\hline tensile strength of Al-Alloy [41] & $270 \mathrm{~N} / \mathrm{mm}$ \\
\hline theoretical bonding strength (calculated) & $6.21 \mathrm{~N} / \mathrm{mm}$ \\
\hline pull-off force Dolly P28 & $38.85 \mathrm{~N} / \mathrm{mm}$ \\
\hline interlocking portion & $15.98 \%$ \\
\hline
\end{tabular}

In this calculation it can be seen that mechanical interlocking accounts for only upto $16 \%$ of the bonding strength. Popov [42], Lipkin et al. [43] and Deng et al. [44] try to quantify the bonding mechanisms in metal-ceramic systems and come to the conclusion that: as the interface surfaces may be in very close proximity van der Waals forces may come into play, so contributing to metalceramic adhesion. The van der Waals forces can be calculated by determining the distance between these two bodies [45].

Figure 20 shows the adhesion tension plotted against the separation distance for two interacting bodies. First estimates after calculation of the van der Waals forces suggest that these interactions will manifest themselves at a nano-meter scale and will be verified in future experiments. 


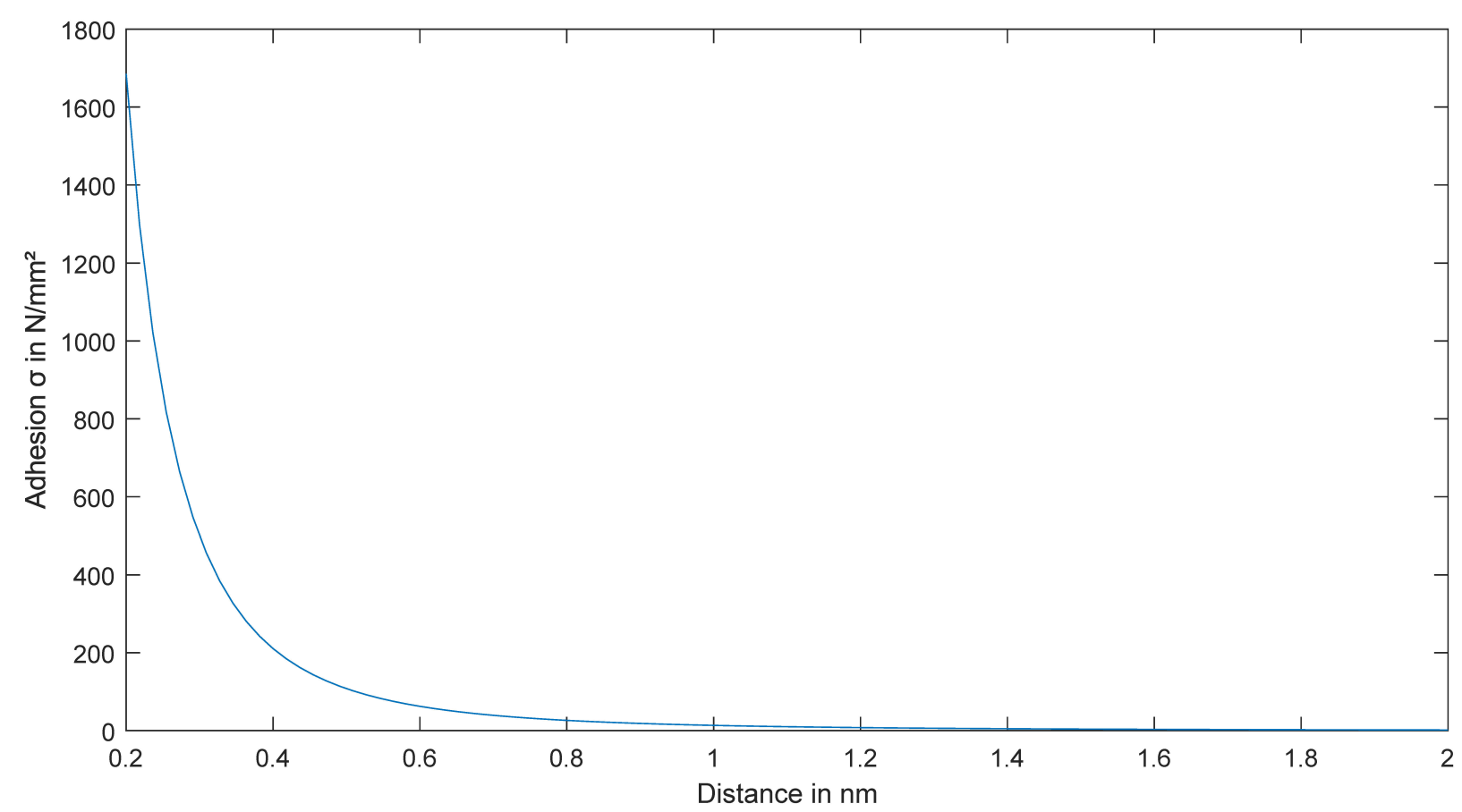

Fig. 20. Van der Waals Forces.

http://mc.manuscripţ̧ętral.com/(site) 


\section{Conclusion}

Friction surfacing of alumina with aluminium proves to be problematic. However, despite the fact that $\mathrm{Al}_{2} \mathrm{O}_{3}$ has a relatively high coefficient of thermal expansion and low thermal shock resistance, specimens have been produced showing encouraging results which are comparable with conventional thermally sprayed coatings.

- Bonding strengths of $48 \mathrm{MPa}$ and coating thicknesses up to $213 \mu \mathrm{m}$ were achieved. The bonding strength obtained are encouraging and offer the potential of a cost effective means for metallizing ceramics with thick films.

- Preheating of the specimens to a minimum of $150^{\circ} \mathrm{C}$ is shown to be important. However, thermal shock induced by the friction process itself leads to crack formation in the alumina substrate and a decrease of strength in that area.

- Friction surfacing places high demands regarding the thermal resilience on the substrate: with flexural strength drops from 258MPa of up to $66 \mathrm{MPa}$ measured.

- Analysis of the joint zone shows no evidence of chemical reactions (inter-metallic compounds) or diffusion.

- Comparing the surface structure of the interface between the substrate and the coating, it can be seen that the aluminium coating, in its viscoplastic state, is flowing into the pores and forming an interlock within. This mechanical interlock accounts for only approximately $16 \%$ of the bonding strength.

- As for the strength deficit, van der Waals forces are likely to contribute.

Refinement of the coating process, experiments with higher preheating temperatures and further investigations on the bonding mechanisms will be conducted in future research. Notably for lowrisk products which will not be exposed to high mechanical loads, friction surfacing of alumina with aluminium could open up new paths for metallizing ceramics with thick films and further integration in metallic assemblies. 


\section{Acknowledgement}

The first part of this work in which coating parameters and their influence on the bonding strength has been researched, was funded by the Dobeneck-Technologie-Stiftung, Germany. The second part concerning bonding mechanisms, received funding by the European Regional Development Fund (EFRE). The authors gratefully acknowledge the financial support received.

\section{Declaration of Conflicting Interests}

Mr. Atil reports grants from Dobeneck-Technologie-Stiftung and grants from European Regional Development Fund (EFRE) during the conduct of the study. The authors declare that they have no known competing financial interests or personal relationships that could have appeared to influence the work reported in this paper.

\section{Data availability}

The raw/processed data required to reproduce these findings cannot be shared at this time as the data also forms part of an ongoing study. 
1. Naidich YV, Zhuravlev VS, Gab II, Kostyuk BD, Krasovskyy VP, Adamovskyy AA, et al. Liquid metal wettability and advanced ceramic brazing. Journal of the European Ceramic Society 2008;28(4):717-28. doi:10.1016/j · jeurceramsoc.2007.07.021.

2. Chuck Walker and Robbin Gourley. Brazing and soldering: Proceedings of the 5th International Brazing and Soldering Conference, Red Rock Casino Resort Spa, Las Vegas, Nevada, USA, 22-25 April 2012. ASM International, Materials Park, Ohio, 2012.

3. Fernie JA. Friction welding of aluminum to ceramics. Materials and Manufacturing Processes 1994;9(3):379-94. doi:10.1080/10426919408934913.

4. Gandra J, Krohn H, Miranda RM, Vilaça P, Quintino L, dos Santos JF. Friction surfacing-a review. Journal of Materials Processing Technology 2014;214(5):1062-93. doi:10.1016/j . jmatprotec.2013.12.008.

5. Stegmueller M, Schindele P, Grant RJ. Inductive heating effects on friction surfacing of stainless steel onto an aluminium substrate, Journal of Materials Processing Technology 2015;216:430-9. doi:10.1016/j · jmatprotec.2014.10.013.

6. Mogl J . Untersuchung und Bewertung der Metallisierung von keramischen Werkstoffen durch Reibbeschichten, Diploma Thesis, University of Applied Sciences Kempten, Germany, 2015.

7. Gandra J, Miranda RM, Vilaça P. Performance analysis of friction surfacing. Journal of Materials Processing Technology 2012;212(8):1676-86. doi:10.1016/j . jmatprotec. 2012. 03.013 .

8. Rao KP, Sankar A, Rafi HK, Ram GDJ, Reddy GM. Friction surfacing on nonferrous substrates: A feasibility study. The International Journal of Advanced Manufacturing Technology 2013;65(5-8):755-62. doi:10.1007/s00170-012-4214-0.

9. Mirlashari A . Friction surfacing onto ceramics. Connect 2009, https: //www.twi-global.com/media-and-events/connect/2009/july-august-2009/ friction-surfacing-onto-ceramics (2009, accessed 25 February 2015).

10. Manteghi S . Fatigue performance of friction welds manufactured both in air and underwater. In: 36th International Conference on Ocean, Offshore and Arctic Engineering, Trond- 
heim, Norway, 25-30 June 2017, paper no. V004T03A017. New York: ASME. doi:10.1115/ OMAE2017-62495.

11. Pietrzak K . Processing of intermetallics with al2o3 or steel joints obtained by friction welding technique. In: Proceedings of the 12th Conference of the European Ceramic Society, Stockholm, Sweden, 1923 June 2011.

12. Fauzi MN, Uday MB, Zuhailawati H, Ismail AB. Microstructure and mechanical properties of alumina-6061 aluminum alloy joined by friction welding. Materials \& Design 2010;31(2):670_ 6. doi:10.1016/j.matdes.2009.08.019.

13. Uday MB, Fauzi MA, Zuhailawati H, Ismail AB. Thermal analysis of friction welding process in relation to the welding of ysz-alumina composite and 6061 aluminum alloy. Applied Surface Science 2012;258(20):8264-72. doi:10.1016/j . apsusc. 2012.05.035.

14. M. B. Uday, M. N. Ahmad-Fauzi, Alias Mohd Noor, and Srithar Rajoo. Current issues and problems in the joining of ceramic to metal. In: Joining technologies. InTech, Rijeka, 2016.

15. Nowotny J. Untersuchungen zum Reibbeschichten von vorzugsweise keramischen Werkstoffen, Diploma Thesis, University of Applied Sciences Kempten, Germany, 2014.

16. Jahanmir S, Ramulu M, Koshy P. Machining of ceramics and composites. In: vol. 53 of Manufacturing engineering and materials processing. New York: Marcel Dekker, 1999. ISBN 9780824701789.

17. Wessel JK. Handbook of advanced materials: Enabling new designs. New Jersey: WileyInterscience, 2004.

18. Auerkari P. Mechanical and physical properties of engineering alumina ceramics. In: vol. 1792 of VTT tiedotteita. Espoo: VTT Technical Research Center of Finland, 1996.

19. Friedrich Ostermann. Anwendungstechnologie Aluminium. 2th ed. Berlin: Springer, 2007. ISBN 9783540711964.

20. Lawn BR. Fracture of Brittle Solids. 2. ed. Cambridge: Cambridge University Press, 1993. ISBN 9780511623127.

21. Sensortherm GmbH. Metis ms08/ms09/mi13/mi16/mi18: Usermanual. 2019. 
22. Chang-Da Wen and Issam Mudawar. Experimental investigation of emissivity of aluminum alloys and temperature determination using multispectral radiation thermometry (mrt) algorithms. Journal of Materials Engineering and Performance, 2002;11(5):551-562. doi:10. $1361 / 105994902770343818$

23. Li P, Li J, Dong H, Ji C. Metallurgical and mechanical properties of continuous drive friction welded copper/alumina dissimilar joints. Materials \& Design 2017;127:311-9. doi:10.1016/ j.matdes.2017.04.093.

24. Minitab Inc. Minitab statistical software. [Computer software]. State College, PA: Minitab, Inc. (www.minitab.com), 2018.

25. Defelsko . Pull-off adhesion tester: Instrucion manual, 2011.

26. Boutar Y, Naïmi S, Mezlini S, Ali MBS. Effect of surface treatment on the shear strength of aluminium adhesive single-lap joints for automotive applications. International Journal of Adhesion and Adhesives 2016;67:38-43. doi:10.1016/j . i jadhadh.2015.12.023.

27. Vitanov VI, Voutchkov II. Process parameters selection for friction surfacing applications using intelligent decision support. Journal of Materials Processing Technology 2005;159(1):2732. doi:10.1016/j.jmatprotec.2003.11.006.

28. Vitanov VI, Voutchkov II , Bedford GM . Neurofuzzy approach to process parameter selection for friction surfacing applications. Surface and Coatings Technology. 2001;140(3):256-262.

29. Antony J. Design of Experiments for Engineers and Scientists. 2nd ed. Amsterdam: Elsevier, 2014. ISBN 9780080994178.

30. Dorey F. The P value: what is it and what does it tell you? Clinical orthopaedics and related research 2010;468(8):2297-8. doi:10.1007/s11999-010-1402-9.

31. Du Prel JB, Hommel G, Röhrig B, Blettner M. Confidence interval or p-value?: part 4 of a series on evaluation of scientific publications. Deutsches Arzteblatt international 2009;106(19):335-9. doi:10.3238/arztebl.2009.0335.

32. Kozak K. Statistics Using Technology. 2. ed. North Carolina: Lulu.com, 2015. ISBN 9781329757257. 
33. Pereira D, Gandra J, Pamies-Teixeira J, Miranda RM, Vilaça P. Wear behaviour of steel coatings produced by friction surfacing. Journal of Materials Processing Technology 2014;214(12):2858-68. doi:10.1016/j · jmatprotec.2014.06.003.

34. Vilaça P. Friction surfacing. Surface modification by solid state processing 2014;:25-72. doi:10.1533/9780857094698.25

35. Barrett GB. The coefficient of determination: Understanding $r^{2}$ and $r^{2}$. The Mathematics Teacher 2000;93(3):230-4.

36. Hosseinabadi N, Sarraf-Mamoory R, Mohammad Hadian A. Diffusion bonding of alumina using interlayer of mixed hydride nano powders. Ceramics International 2014;40(2):3011-21. doi:10.1016/j.ceramint.2013.10.006.

37. Choi DH, Ahn BW, Lee CY, Yeon YM, Song K, Jung SB. Formation of intermetallic compounds in al and $\mathrm{mg}$ alloy interface during friction stir spot welding. Intermetallics 2011;19(2):125-30. doi:10.1016/j.intermet.2010.08.030.

38. Uday MB, Ahmad-Fauzi MN. Joint properties of friction welded 6061 aluminum alloy/yszalumina composite at low rotational speed. Materials \& Design 2014;59:76-83. doi:10.1016/ j.matdes.2014.02.020.

39. Kollenberg W. Technische Keramik: Grundlagen, Werkstoffe, Verfahrenstechnik. 2. ed. Essen: Vulkan-Verl., 2009. ISBN 9783802729539.

40. Caroline A. Schneider, Wayne S. Rasband, and Kevin W. Eliceiri. Nih image to imagej: 25 years of image analysis. Nature Methods, 2012;9(7):671-675.

41. AMCO Metall-Service GmbH . Technical Datasheet: EN AW-5083 (AlMg4,5Mn) 2018.

42. Popov VL. Kontaktmechanik und Reibung. Berlin: Springer, 2010. ISBN 9783642133015.

43. Lipkin DM, Israelachvili JN, Clarke DR. Estimating the metal-ceramic van der waals adhesion energy. Philosophical Magazine A 1997;76(4):715-28. doi:10.1080/01418619708214205.

44. Deng K, Yu Z, Zhou J, Liu H, Zhang S. Atomistically derived metal-ceramic interfaces cohesive law based on the van der waals force. Engineering Fracture Mechanics 2013;111:98-105. doi:10.1016/j.engfracmech.2013.09.007. 
45. Komarov SV, Romankov SE. Mechanical metallization of alumina substrate through shot impact treatment. Journal of the European Ceramic Society 2014;34(2):391-9. doi:10.1016/ j.jeurceramsoc.2013.08.022. 


\section{List of Tables}

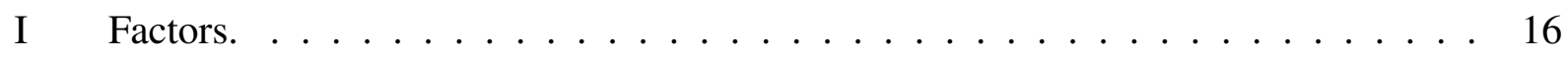

II $\quad$ Analysis of variance for coating thickness. . . . . . . . . . . . . . . . . . 19

III Analysis of variance for coating thickness with only significant factors. . . . . . . 20

IV $\quad$ Analysis of variance for bonding strength. . . . . . . . . . . . . . . . . . . . . 24

$\mathrm{V} \quad$ Analysis of variance for bonding strength with only significant factors. . . . . . . . 25

VI Interlocking portion. . . . . . . . . . . . . . . 36 


\section{List of Figures}

$1 \quad$ Friction surfacing $[6] . \ldots \ldots \ldots \ldots \ldots$

2 Machine set-up [15]. . . . . . . . . . . . . . . . 6

3 Sketches showing (a) clamping device design [6] and (b) specimen dimensions. . . 8

4 Cracking at the centre of the specimen. . . . . . . . . . . . . . 9

5 Pictures showing prepared specimen (a) before surfacing , and (b) after surfacing. . 11

6 Pull-off test: (a) schematic of arrangement, (b) the hollow core drill, and (c) the

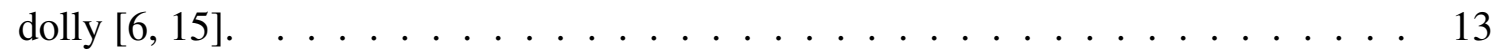

$7 \quad$ Profiles of coated specimen: (a) Side-section, and (b) cross-section [6]. . . . . . . . 14

$8 \quad$ Thermal shock tests: (a) equipment,(b) sample holder, and (c) four-Point bending test schematic. . . . . . . . . . . . . . . . . . . 17

$9 \quad$ Probability plot for coating thickness. . . . . . . . . . . . . . 21

$10 \quad$ Interaction plots for coating thickness, $[\mu \mathrm{m}] . \ldots \ldots \ldots \ldots$. . . . . . . . 22

11 Probability plot for bonding strength. . . . . . . . . . . . . . . . 25

12 Interaction plots for bonding strength, $[\mathrm{MPa}] . \ldots \ldots \ldots$. . . . . . . . 26

13 Thermal plots at a spindle rotational speed of (a) 3000rpm and (b) 6000rpm. . . . . 28

14 (a) Dolly with alumina breakout [6], (b) substrate cross-section [15], and (c) breakout characteristics. . . . . . . . . . . . . . . . . . . . . . . 29

$15 \quad$ Flexural strength vs. change in temperature, $\Delta \mathrm{T} \ldots \ldots \ldots \ldots$

16 SEM image of coated substrate surface. . . . . . . . . . . . . . . . 32

$17 \quad$ 3D surface profile of (a) substrate, and (b) pulled-off coating. . . . . . . . . . . 33

$18 \quad$ SEM image of the interface: (a) without processing, and (b) mapped image. . . . . 34

19 Interlocked surface area: (a) dolly surface, (b) substrate surface, (c) dolly scanned area, and $(\mathrm{d})$ image processed. . . . . . . . . . . . . . . . . 35

20 Van der Waals Forces. . . . . . . . . . . . . . . . . . . . . . 37 